\title{
Antioxidant Treatment Reduces Formation of Structural Cores and Improves Muscle Function in RYR1 ${ }^{\text {Y522S/WT }}$ Mice
}

\author{
Antonio Michelucci, ${ }^{1,2}$ Alessandro De Marco, ${ }^{1,2}$ Flavia A. Guarnier, ${ }^{3}$ Feliciano Protasi, ${ }^{1,4}$ and \\ Simona Boncompagni ${ }^{1,2}$ \\ ${ }^{1}$ Center for Research on Aging and Translational Medicine (CeSI-MeT), University G. d'Annunzio of Chieti, 66100 Chieti, Italy \\ ${ }^{2}$ Department of Neuroscience, Imaging, and Clinical Sciences (DNICS), University G. d'Annunzio of Chieti, 66100 Chieti, Italy \\ ${ }^{3}$ Department of General Pathology, University Estadual de Londrina, 86057-970 Londrina, PR, Brazil \\ ${ }^{4}$ Department of Medicine and Aging Science (DMSI), University G. d'Annunzio of Chieti, 66100 Chieti, Italy
}

Correspondence should be addressed to Simona Boncompagni; simona.boncompagni@unich.it

Received 6 April 2017; Accepted 13 June 2017; Published 10 September 2017

Academic Editor: Marko D. Prokić

Copyright ( $\odot 2017$ Antonio Michelucci et al. This is an open access article distributed under the Creative Commons Attribution License, which permits unrestricted use, distribution, and reproduction in any medium, provided the original work is properly cited.

\begin{abstract}
Central core disease (CCD) is a congenital myopathy linked to mutations in the ryanodine receptor type 1 (RYR1), the sarcoplasmic reticulum $\mathrm{Ca}^{2+}$ release channel of skeletal muscle. CCD is characterized by formation of amorphous cores within muscle fibers, lacking mitochondrial activity. In skeletal muscle of RYR1 ${ }^{\mathrm{Y} 522 \mathrm{~S} / \mathrm{WT}}$ knock-in mice, carrying a human mutation in RYR1 linked to malignant hyperthermia $(\mathrm{MH})$ with cores, oxidative stress is elevated and fibers present severe mitochondrial damage and cores. We treated RYR1 ${ }^{\mathrm{Y} 522 \mathrm{~S} / \mathrm{WT}}$ mice with $\mathrm{N}$-acetylcysteine (NAC), an antioxidant provided ad libitum in drinking water for either 2 or 6 months. Our results show that 2 months of NAC treatment starting at 2 months of age, when mitochondrial and fiber damage was still minimal, (i) reduce formation of unstructured and contracture cores, (ii) improve muscle function, and (iii) decrease mitochondrial damage. The beneficial effect of NAC treatment is also evident following 6 months of treatment starting at 4 months of age, when structural damage was at an advanced stage. NAC exerts its protective effect likely by lowering oxidative stress, as supported by the reduction of 3-NT and SOD2 levels. This work suggests that NAC administration is beneficial to prevent mitochondrial damage and formation of cores and improve muscle function in RYR $1^{\mathrm{Y} 522 \mathrm{~S} / \mathrm{WT}}$ mice.
\end{abstract}

\section{Introduction}

Central core disease (CCD), one of the most common human congenital myopathies, is an inherited neuromuscular disorder characterized by hypotonia and proximal muscle weakness, which cause motor developmental delay in children $[1,2]$. Diagnosis of CCD is confirmed by histological examination of muscle biopsies showing amorphous central areas (i.e., cores) lacking glycolytic/oxidative enzymes and mitochondria [3]. Disorganization of contractile and sarcotubular systems is also typical in cores [4]. To date, management of patients/children is essentially supportive and based on physiotherapic approaches and no curative treatments are available. Hence, a deeper understanding of the molecular mechanisms underlying mitochondrial damage and formation of cores in CCD is needed to develop effective therapeutic interventions.

In humans, about $90 \%$ of CCD cases are linked to mutations in the ryanodine receptor type 1 (RYR1) gene [5], encoding for the sarcoplasmic reticulum (SR) $\mathrm{Ca}^{2+}$ release channel of skeletal muscle. RYR1 is a large protein of about $2200 \mathrm{kDa}$ specifically localized in calcium release units (CRUs), the intracellular junctions formed by the close apposition of transverse-tubules (TT) to the SR. RYR1 in CRUs is part of macromolecular complex deputed to excitationcontraction (EC) coupling, the mechanism that allows transduction of the action potential into $\mathrm{Ca}^{2+}$ release from the SR $[6,7]$. Mutations in RYR1 gene, which causes abnormalities in the opening probability of the $\mathrm{Ca}^{2+}$ channel, are also often associated to malignant hyperthermia $(\mathrm{MH})$ susceptibility, 
an inherited pharmacogenetic subclinical myopathy, characterized by a life-threatening hypermetabolic response to commonly used halogenated/volatile anesthetics (i.e., halothane, isofluorane) [8,9]. An association between CCD and $\mathrm{MH}$ exists as individuals with $\mathrm{MH}$ may have muscle biopsies with cores $[10,11]$, while CCD patients may be at risk for hyperthermic episodes during anesthetic procedures, as also confirmed by in vitro caffeine-halothane contracture testing (either IVCT, in vitro contracture test, or the CHCT, caffeine-halothane contracture test), performed on muscle biopsies [2, 12-14].

In the 2006, an animal model (RYR1-Y522S knock-in mice) carrying a human gain-of-function mutation associated to $\mathrm{MH}$, skeletal muscle weakness, and formation of cores was generated and characterized [10]. Heterozygous Y522S mice (RYR1 ${ }^{\mathrm{Y} 522 \mathrm{~S} / \mathrm{WT}}$ ) suffer lethal MH crises when acutely exposed to both anesthetics and heat $[15,16]$ and develop structural cores [17]. Muscles of RYR1 ${ }^{\text {Y522S/WT }}$ mice also exhibit a marked temperature-dependent increase in resting myoplasmic $\mathrm{Ca}^{2+}$, excessive oxidative stress [16], and enhanced mitochondrial superoxide flashes activity [18]. The current view of the molecular mechanisms underlying the phenotype of RYR1 ${ }^{\mathrm{Y} 522 \mathrm{~S} / \mathrm{WT}}$ mice is that the Y522S mutation promotes a significant increase of the opening probability of the RYR1 channel, which causes SR Ca ${ }^{2+}$ leak and overproduction of reactive oxygen and nitrogen species (ROS and RNS), as a consequence of the increased $\mathrm{Ca}^{2+}$-dependent mitochondrial activity. In turn, excessive ROS and RNS would determine nitrosylation/glutathionylation of RYR1, oxidative modifications responsible of further increase of RYR1 opening probability [16]. The feed-forward mechanism triggered by ROS/RNS would in principle play a pivotal role: (i) acutely, in anesthetic- and heat-induced lethal $\mathrm{MH}$ episodes and (ii) chronically, in mitochondrial damage and development of cores, two types of structural alterations that resemble CCD in humans [17].

Here, we treated RYR1 ${ }^{\text {Y522S/WT }}$ mice with $\mathrm{N}$ acetylcysteine (NAC), a potent antioxidant provided ad libitum in drinking water $(1 \% w / v)$ for either 2 months (2-4 months of age, starting when mitochondrial and fiber damage was still minimal) or 6 months (4-10 months of age; starting when structural damage was already at an advanced stage) [17], and evaluated the effect of this pharmacological treatment on formation of cores, muscle function, mitochondrial damage, and levels of oxidative stress in extensor digitorum longus (EDL) muscles. The results collected in this study indicate that NAC administration is beneficial to prevent/reduce mitochondrial damage and formation of cores and improve muscle function in RYR1 $1^{\mathrm{Y} 522 \mathrm{~S} / \mathrm{WT}}$ mice.

\section{Materials and Methods}

2.1. RYR1 $1^{Y 522 S / W T}$ Mice. Heterozygous Y522S mice were generated as previously described [15]. Mice were housed in microisolator cages at $20^{\circ} \mathrm{C}$ in a $12 \mathrm{hr}$ light/dark cycle and provided free access to water and food. Animals used in this study were all males, and analyses were carried out in EDL muscles. All experiments were conducted according to the Directive of the European Union 2010/63/UE, and animal protocols were approved by the Committee on the Ethics of
Animal Experiments of the University of Chieti (15/2011/ CEISA/COM). All surgeries were made to minimize animal suffering; animals were anesthetized and then sacrificed by cervical dislocation.

2.2. NAC Treatment. RYR $1^{\mathrm{Y} 522 \mathrm{~S} / \mathrm{WT}}$ mice were randomly assigned to the experimental groups: untreated or NAC-

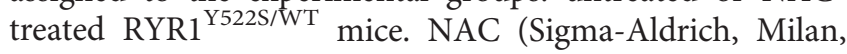
Italy) was provided in vivo in drinking water at the final concentration of $1 \%$ weight/volume $(1 \% w / v)$ as previously described [19] for either 2 months (from 2-4 months of age) or 6 months (from 4-10 months of age).

2.3. Preparation and Analysis of Samples in Light and Electron Microscopy (EM). EDL muscles were dissected, fixed at room temperature with $3.5 \%$ glutaraldehyde in $0.1 \mathrm{M}$ $\mathrm{NaCaCo}$ buffer ( $\mathrm{pH} 7.2$ ), and kept at $4^{\circ} \mathrm{C}$ in fixative until further use. Small bundles of fixed muscles were then postfixed, embedded, stained en-block, and sectioned as previously described $[17,20]$. For EM, ultrathin sections ( $50 \mathrm{~nm})$ were examined after staining in 4\% uranyl acetate and lead citrate, with a Morgagni Series 268D electron microscope (FEI Company, Brno, Czech Republic), equipped with Megaview III digital camera (Olympus Soft Imaging Solutions GmbH, Munster, Germany) at $60 \mathrm{kV}$. For histology, $700 \mathrm{~nm}$ thick sections were stained in a solution containing $1 \%$ Toluidine blue $\mathrm{O}$ and $1 \%$ sodium borate tetra in distilled water for $3 \mathrm{~min}$ on a hot plate at $55-60^{\circ} \mathrm{C}$. After washing and drying, sections were finally mounted with mounting medium (DPX Mountant for histology, Sigma-Aldrich, Milan, Italy).

2.4. Quantitative Analysis in Histology and EM Preparations. Consider the following:

(1) Histological sections were examined under direct illumination and/or phase contrast optics with a Leica DMLB fluorescence microscope (Leica Microsystem, Vienna, Austria), and individual EDL fibers were visually scored for the presence of either unstructured or contracture cores as in [17].

(2) Number/area, size, and volume of mitochondria (and number/area of CRUs and mitochondria CRU pairs) were determined in EDL fibers as follows: (a) Mitochondrial volume was determined using the well-established stereology point-counting technique $[21,22]$ in micrographs taken from transversal sections at magnification 7100x. Briefly, after superimposing an orthogonal array of dots at a spacing of $0.20 \mu \mathrm{m}$ to the electron micrographs, ratio between numbers of dots falling within mitochondrial profiles and total number of dots covering the whole image was used to calculate the relative fiber volume occupied by mitochondria. (b) Number of severely damaged mitochondria was counted in longitudinal sections, and their frequency was reported as an average number in $100 \mu \mathrm{m}^{2}$ and as $\%$ of mitochondria evaluated. Mitochondria were classified as severely damaged as previously described [17]. (c) Average mitochondrial size $\left(\mathrm{nm}^{2}\right)$ of apparently normal 
mitochondria was measured in longitudinal sections using the analysis software of the EM digital camera (Olympus Soft Imaging Solutions GmbH, Munster, Germany). Severely damaged mitochondria, included in (b), were excluded from this analysis. (d) Number/ area of CRUs, mitochondria, and mitochondria CRU pairs was also evaluated in longitudinal sections and reported as the average number in $100 \mu \mathrm{m}^{2}$.

2.5. Immunolabeling and Confocal Microscopy (CM). EDL muscles were dissected from sacrificed mice and fixed with paraformaldehyde $2 \%$ for $1-2 \mathrm{hrs}$ at room temperature. Small bundles of muscles were processed for double immunostaining as previously described [23]. Primary antibodies used (a) mouse monoclonal anti-RyR1/RyR3 34C (1:20) (Developmental Studies Hybridoma Bank, University of Iowa, Iowa, USA) and (b) rabbit polyclonal antimitochondrial preprotein translocases of the outer membrane, TOM20 (1:50) (Santa Cruz Biotechnology, Inc., Dallas, TX, USA). Secondary antibodies used (a) Cy5-labeled goat anti-mouse IgG and (b) Cy3-labeled goat anti-rabbit IgG (Jackson ImmunoResearch Laboratories, West Grove, PA, USA). Images were acquired using a Zeiss LSM510 META laser-scanning confocal microscope system (Zeiss, Jena, Germany) equipped with Zeiss Axiovert 200 inverted microscope and a Plan Neofluar oil-immersion objective (63X/1.3 NA). Negative controls for each immunostaining assay were performed by immunolabeling of samples with only secondary antibodies.

2.6. Quantitative Plasma and Serum Analyses. Blood levels of creatine kinase $(\mathrm{CK})$ and lactate dehydrogenase $(\mathrm{LDH})$, markers of fiber damage, were spectrophotometrically measured in serum $(\mathrm{CK})$ and plasma (LDH) samples obtained from mice as previously described [19], by using a Screen Touch Master spectrophotometer (Hospitex Diagnostic, Sesto Fiorentino, Italy).

2.7. Calpain Activity. The activity of calpain was measured in total hind limb muscle homogenates, by a chemiluminescence assay using a Calpain Protease Assay kit (CalpainGlo Protease Assay ${ }^{\circledR}$, Promega; Madison, WI, USA). The assay provides a proluminescent calpain substrate, in a buffer system optimized for calpain and luciferase activities. During the assay, calpain cleavage of the substrate generates a glowtype luminescent signal produced by the luciferase reaction. In this homogeneous, coupled-enzyme format, the signal is proportional to the amount of calpain activity present in the sample [24]. In this study, total hind limb muscle homogenates were prepared at a concentration of $6.25 \mathrm{mg} / \mathrm{mL}$ in $10 \mathrm{mM} \mathrm{KH}_{2} \mathrm{PO}_{4}$ buffer, $\mathrm{pH} 7.4$ in $0.9 \% \mathrm{NaCl}$ and finally processed according to the manufacturer's instructions. Results are expressed as calpain activity/mg of muscle tissue.

2.8. Carbonyl Protein Content. Protein carbonyl group formations are classic and immediate biomarkers of oxidative modification to proteins, which may promote disorganization of contractile structures [25, 26]. 2,4-Dinitrophenylhydrazine (DNPH) tagging of protein carbonyls has been one of the most common measures of oxidative stress and consequent protein damage. Carbonyl protein content was measured as previously described [25], with modifications. Briefly, a mix of total hind limb muscles $(50 \mathrm{mg} / \mathrm{mL})$ was homogenized in $50 \mathrm{mM}$ phosphate buffer, $1 \mathrm{mM}$ ethylenediamine tetraacetic acid, $\mathrm{pH} 7.4$, and tissue samples were centrifuged at $600 \mathrm{~g} / 10 \mathrm{~min} / 4^{\circ} \mathrm{C}$. A volume of $200 \mu \mathrm{L}$ of DNPH was added to $200 \mu \mathrm{L}$ of supernatant and incubated at room temperature. After a $30 \mathrm{~min}$ incubation, $100 \%$ trichloroacetic acid (TCA) was added and samples were placed on ice for $5 \mathrm{~min}$ and then spinned at maximal speed for $2 \mathrm{~min}$. Supernatants were discarded without disturbing pellets, which were washed in cold acetone and placed at $-20^{\circ} \mathrm{C}$ for $5 \mathrm{~min}$. Then, acetone was carefully removed, and pellets were dissolved in $0.5 \mathrm{~mL} 6 \mathrm{M}$ guanidine hydrochloride to be read at $375 \mathrm{~nm}$. To calculate the protein carbonyl content, the following formula was used: $\mathrm{C}=[(\mathrm{OD} 375 \mathrm{~nm}) / 6.364 \times(100)]$ $\mathrm{nmol} /$ well, where 6.364 is the extinction coefficient using the enclosed 96-well plates in $\mathrm{mM} \quad(=22 \mathrm{mM}-1 \mathrm{~cm}-$ $1 \times 0.2893 \mathrm{~cm}$ path length in well). Results were expressed as nmol carbonyl/mg of total protein, which were quantified in each sample at $280 \mathrm{~nm}$.

2.9. Western Blot Analyses. For assessment of 3-nitrotyrosyne (3-NT) content, mixed muscles from hind limb were homogenized on ice in a buffer containing $50 \mathrm{mM}$ Tris- $\mathrm{HCl}, \mathrm{pH} 7.4$; $1 \%$ NP-40; $0.25 \%$ sodium deoxycholate; $150 \mathrm{mM} \mathrm{NaCl}$; $1 \mathrm{mM}$ EDTA; $1 \mathrm{mM}$ PMSF; protease inhibitors. After centrifugation at $10000 \mathrm{~g}$ for $15 \mathrm{~min}$ at $4^{\circ} \mathrm{C}$, supernatants were collected and total protein concentration was determined using Bio-Rad Protein assay (Bio-Rad laboratories, CA). $40 \mu \mathrm{g}$ of total proteins was separated by SDS-PAGE in a $10 \%$ polyacrylamide gel, followed by western blotting using anti 3-NT mouse monoclonal antibody (1:500, Merk Millipore, Milan, Italy) and a horseradish peroxidase(HRP-) conjugated anti-mouse secondary antibody (Merck Millipore, Darmstadt, Germany). Visualization and densitometric quantification of signals were done using the imaging system Alliance Mini 4 with Alliance 1D MAX software (UVItec, Cambridge, UK). After measuring 3-NT, the membranes were stripped by Tris/SDS buffer with 2mercaptoethanol. After blocking, the membranes were incubated with anti-glyceraldehyde-3-phosphate dehydrogenase (GAPDH) antibody (OriGene, Rockville, MD, USA) for normalization to the protein content within each band.

For assessment of $\mathrm{Cu} / \mathrm{Zn}$-superoxide dismutase (SOD1) and $\mathrm{Mn}$-superoxide dismutase (SOD2) protein levels, western blot experiments were performed as follows: mixed muscles from hind limb were homogenized on ice in RIPA buffer (50 mM Tris- $\mathrm{HCl}, \mathrm{pH} 8.0 ; 150 \mathrm{mM} \mathrm{NaCl} ; 0.5 \%$ sodium deoxycholate; $0.1 \%$ SDS; $1 \%$ NP-40; $0.1 \mathrm{mM} \mathrm{PMSF;} \mathrm{protease}$ inhibitors). Homogenates were centrifuged at $10000 \mathrm{~g}$ for $15 \mathrm{~min}$ at $4^{\circ} \mathrm{C}$, supernatants were collected, and total protein concentration was determined using Bio-Rad Protein assay (Bio-Rad laboratories, Hercules, CA, USA). Protein samples $(5 \mu \mathrm{g})$, solubilized in $2 \times$ sample buffer $(125 \mathrm{mM}$ Tris- $\mathrm{HCl}$, pH 6.8; 4\% SDS; 20\% glycerol; 0.004\% bromophenol blue; $10 \%$ 2-mercaptoethanol), were loaded on a $12 \%$ acrylamide gel, separated by SDS-PAGE, and transferred to nitrocellulose membrane. Membranes were probed using primary 
antibodies against SOD1 $(1: 1000$, Santa Cruz Biotechnology, Dallas, TX, USA), SOD2 (1:2000, Santa Cruz Biotechnology, Dallas, TX, USA), and GAPDH ( $1: 10000$, OriGene, Rockville, $\mathrm{MD}$, USA) overnight at $4^{\circ} \mathrm{C}$. HRP-conjugated antimouse or rabbit (1:10000, Merck Millipore, Darmstadt, Germany) was used as a secondary antibody, and peroxidase activity was detected using an enhanced chemiluminescence (ECL) kit (Perkin Elmer, Waltham, MA, USA). The bands were visualized, and densitometric quantification of signals was performed using the imaging system Alliance Mini 4 with Alliance 1D MAX software (UVItec, Cambridge, UK).

2.10. Grip Strength Test. Strength developed by mice during instinctive grasp was measured as previously described [27]. Briefly, mice were held by the tail and allowed to firmly grasped to a metal grating, connected to the shaft of a Shimpo Fgv 0.5X force transducer (Metrotec Group, Lezo, Spain), with fore and hind limbs before a gentle pull was exerted on the tail. Measurements of peak force generated by each mouse were repeated three times with appropriate intervals (at least $30 \mathrm{sec}$ ) to avoid fatigue, and the highest value of peak force (normalized to total body mass) measured before each experiment was used.

2.11. Force and Contraction Kinetics of Intact EDL Muscles. EDL muscles were dissected from WT, untreated $\mathrm{RYR}_{1}{ }^{\mathrm{Y} 522 \mathrm{~S} / \mathrm{WT}}$, and NAC-treated RYR $1^{\mathrm{Y} 522 \mathrm{~S} / \mathrm{WT}}$ mice and placed in a dish containing Krebs solution with the following composition in mM: $118 \mathrm{NaCl}, 4.7 \mathrm{KCl}, 1.2 \mathrm{MgSO}_{4}, 2.5$ $\mathrm{CaCl}_{2}, 1.2 \mathrm{KH}_{2} \mathrm{PO}_{4}, 25 \mathrm{NaHCO}_{3}$, and 11 glucose. Individual EDLs were then pinned, tied with fine silk sutures at each end, and mounted vertically between two platinum electrodes immersed in an organ chamber filled with Krebs solution and attached to a servo motor and force transducer (model 1200A, Aurora Scientific, ON, Canada). Temperature was kept between $23-25^{\circ} \mathrm{C}$. Before starting the experimental protocol, stimulation level and optimal muscle length $\left(L_{0}\right)$ were determined using a series of $80 \mathrm{~Hz}$-tetani in order to stretch the muscle to the length that generated maximal force $\left(F_{0}\right)$. After optimization of the stimulation conditions, EDL muscles were subjected to a force-frequency protocol based on a series of train pulses of $500 \mathrm{~ms}$ duration each as follows (in $\mathrm{Hz}$ ): 1, 5, 10, 20, 40,60, 80, 100, 120 , and 140. After $5 \mathrm{~min}$ at rest, the same EDL muscles were subjected to a single-sustained high frequency tetanus $(120 \mathrm{~Hz}, 2 \mathrm{sec})$. Muscle force was recorded using a dynamic muscle control (DMC) software and analyzed using dynamic muscle analysis (DMA) software (both from: Aurora Scientific, ON, Canada). Specific force $\left(\mathrm{mN} / \mathrm{mm}^{2}\right)$ was calculated by normalizing the absolute force $(\mathrm{mN})$ to the cross sectional area $\left(\mathrm{CSA}, \mathrm{mm}^{2}\right)$ obtained as the following: muscle wet weight $(\mathrm{mg}) / L_{0}(\mathrm{~mm}) * 1.06\left(\mathrm{mg} / \mathrm{mm}^{3}\right)$.

2.12. Statistical Analyses. Statistical significance for the quantitative analysis of fibers presenting structural alterations (i.e., unstructured and contracture cores) was evaluated using twotailed Fisher's exact test. One-way ANOVA followed by post hoc Tukey test was used for statistical analyses of all other experiments except for those regarding the time courses of in vivo grip strength and the force-frequency of intact EDL muscles, in which repeated measures ANOVA was used followed by post hoc Tukey test for the pairwise comparisons. In all cases, differences were considered statistically significant at $p<0.05$. Two-tailed Fisher's exact tests were performed using GraphPad software, whereas one-way ANOVA and repeated measures ANOVA were performed using Origin 8.0 software.

\section{Results}

The effect of NAC treatment on structure, function, and oxidative stress levels of EDL muscles from RYR $1^{\mathrm{Y} 522 \mathrm{~S} / \mathrm{WT}}$ mice was evaluated at (a) 4 months of age after 2 months of treatment (starting when mitochondrial and fiber damage was still minimal) and at (b) 10 months of age after 6 months of treatment (starting when mitochondrial damage was already at an advanced stage) [17]. In the manuscript, we will refer to 2 and 6 months of treatment as short-term and long-term NAC treatments, respectively.

3.1. NAC Treatment Reduces Formation of Structural Cores, Fiber Damage, and Proteolytic Degradation in EDL Muscles of RYR $1^{\text {Y522S/WT }}$ Mice. Skeletal fibers from RYR1 ${ }^{\mathrm{Y} 522 \mathrm{~S} / \mathrm{WT}}$ mice develop unstructured and contracture cores [17]. To evaluate the effect of NAC in reducing formation of cores, using histological sections, we analyzed and classified fibers in three different categories, as previously described [17]: (a) normal fibers, presenting a well-preserved cross striation pattern (Figure 1(a)); (b) fibers with unstructured cores, presenting extensive areas lacking cross striation (Figure 1(b), asterisks); and (c) fibers with contracture cores, exhibiting areas of extreme sarcomere shortening (Figure 1(c), arrows). Quantitative analysis of the relative percentage of fibers, presenting the different features, indicates that NAC treatment was effective in preventing the formation of structural cores (Figure 1(d) and Table S1 available online at https://doi.org/10.1155/2017/6792694). Specifically, unstructured and contracture cores, which are not present in WT fibers, were found, respectively, in $14 \%$ and $23 \%$ of fibers in RYR $1^{\mathrm{Y} 522 \mathrm{~S} / \mathrm{WT}} \mathrm{EDL}$ muscles (Figure 1(d)). However, following NAC treatment, the number of RYR1 ${ }^{\mathrm{Y} 522 \mathrm{~S} / \mathrm{WT}}$ EDL fibers containing unstructured and contracture cores was significantly reduced to $6 \%$ and $3 \%$, respectively (Figure 1(d)). The decrease in the number of fibers containing cores results in a parallel increase in the percentage of normal fibers (from 63 to 92\%). Data plotted in Figure 1 are available in Table S1.

As fiber damage results in changes in blood parameters, we performed biochemical measurements of markers of muscle damage in blood samples. Specifically, we evaluated serum and plasma levels of the muscle-specific isoforms of creatine kinase (CK, in serum) and lactate dehydrogenase (LDH, in plasma) [28]. Consistent with the higher percentage of fibers presenting structural alterations, in RYR ${ }^{\mathrm{Y} 522 \mathrm{~S} / \mathrm{WT}}$ samples, both CK and LDH levels were about 30\% higher than those in aged-matched WT mice (Figures 1(e) and 1(f)). The protective effect of NAC was confirmed by these experiments: 2 months of NAC treatment was effective in 


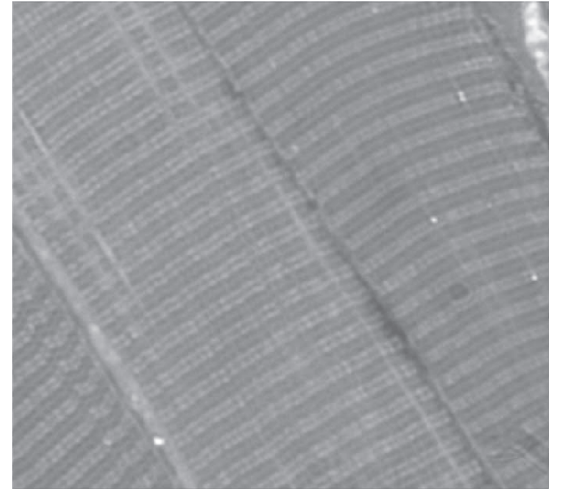

Normal fibers

(a)

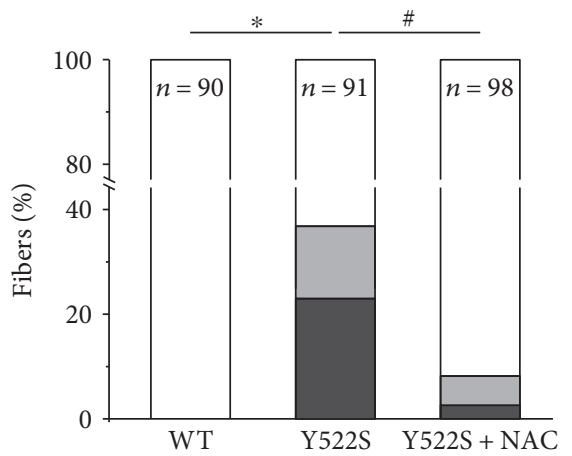

(d)

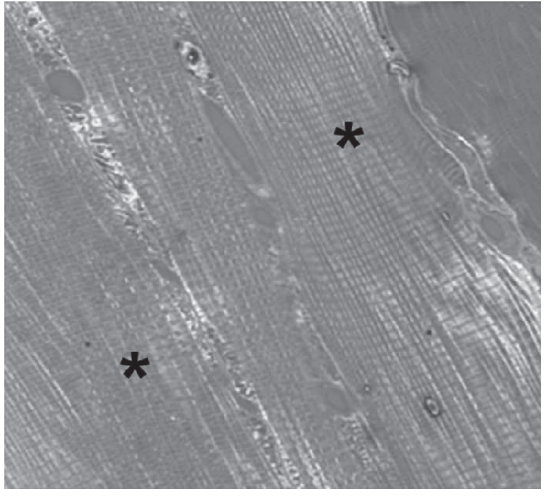

Fibers with unstructured cores

(b)

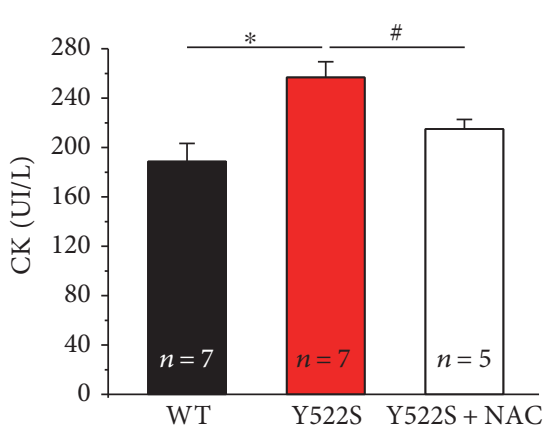

(e)

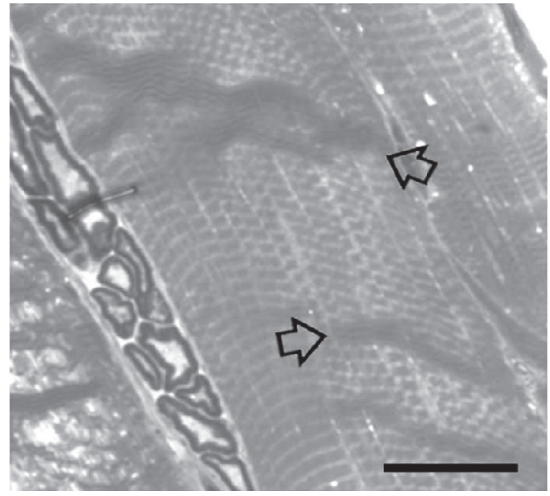

Fibers with contracture cores

(c)

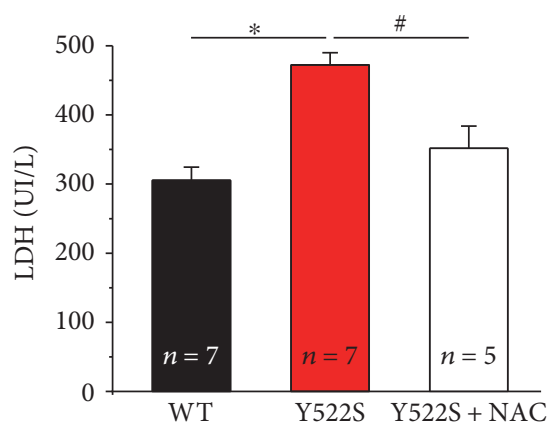

(f)

FIGURE 1: Structural cores and blood markers of muscle damage (CK and LDH) at 4 months of age. (a-c) Representative histological images of normal fibers (a), fibers with unstructured cores (b), and fibers with contracture cores (c). (d) Percentage of EDL fibers presenting the features classified in $(\mathrm{a}-\mathrm{c})$ (white: normal fibers; grey: fibers with unstructured cores; and dark grey: fibers with contracture cores). See also Table S1. (e and f) Serum levels of creatine kinase (CK) and lactate dehydrogenase (LDH). In (e) and (f), data are given as mean \pm SEM; ${ }^{*} p<0.05$, WT versus RYR $1^{\mathrm{Y} 522 \mathrm{~S} / \mathrm{WT}}$ mice; ${ }^{\#} p<0.05$, untreated RYR $1^{\mathrm{Y} 522 \mathrm{~S} / \mathrm{WT}}$ versus NAC-treated RYR $1^{\mathrm{Y} 522 \mathrm{~S} / \mathrm{WT}}$ mice. In $(\mathrm{d}), n=$ number of fibers analyzed; in (e-f), $n=$ number of mice. Scale bar: $10 \mu \mathrm{m}$.

reducing the amount of both $\mathrm{CK}$ and $\mathrm{LDH}$ in blood samples from RYR1 ${ }^{\text {Y522S/WT }}$ mice to values closer to that of WT (Figures 1(e) and 1(f)), a result consistent with the significant reduction in the incidence of fibers presenting unstructured and contracture cores (Figure 1(d)).

We also analyzed EDL muscles using a combination of immunofluorescence for CM and EM and assessed proteolytic degradation by measuring calpain activity and carbonyl protein content (Figure 2). In adult EDL fibers from WT mice, both CRUs, marked with an antibody that recognized RYR1, and mitochondria, marked with an antibody that labels translocase of outer mitochondrial membrane 20 homolog (TOM20), form double rows of cross striation (Figure 2(a) and inset). This fluorescence pattern is consistent with positioning of both CRUs and mitochondria at the I band, on either side of the $Z$-line (pointed by arrows in Figures 2(b) and 2(f); see [20] for additional detail on the specific disposition of CRUs and mitochondria in adult skeletal fibers). In RYR1 ${ }^{\mathrm{Y} 522 \mathrm{~S} / \mathrm{WT}}$ EDL fibers, this precise cross striation pattern was often compromised (arrow in Figure 2(c) and inset). These areas lacking staining (pointed by arrows in Figure 1(c)) reflect the presence of contracture cores, visible in EM as regions with shortened sarcomeres (arrow in Figure 2(d)). NAC treatment in RYR1 ${ }^{\mathrm{Y} 522 \mathrm{~S} / \mathrm{WT}}$ mice restored the cross striation pattern in the large majority of fibers (consistent with reduction of fibers with cores; Figure $1(\mathrm{~d})$ ): both red and green staining were perfectly transversal (Figure 2(e)), while ultrastructure of myofibrils and sarcomeres at the EM examination was virtually indistinguishable from that of WT fibers (compare Figures 2(b) and $2(\mathrm{f})$ ).

The RYR1-Y522S mutation causes leak of $\mathrm{Ca}^{2+}$ from the SR [16]. As excessive myoplasmic $\mathrm{Ca}^{2+}$ concentration activates calpains that cleave a variety of substrates, including myofibrillar proteins $[24,29,30]$, calpain-mediated degradation could contribute to the ultrastructural alterations observed in RYR1 ${ }^{\text {Y522S/WT }}$ muscle fibers. We measured the total calpain activity, which was markedly elevated in muscles from RYR $1^{\mathrm{Y} 522 \mathrm{~S} / \mathrm{WT}}$ compared to that from WT (Figure 2(g)), but lowered to levels very similar to those from WT following NAC treatment (Figure 2(g)). In addition, we also evaluated the total carbonyl protein content in the same muscle homogenates, an important biomarkers of oxidative modification of proteins $[25,26]$. Also in this 


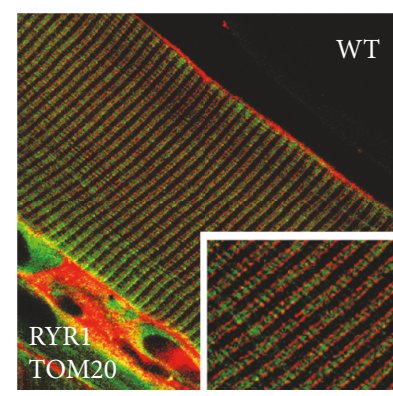

(a)

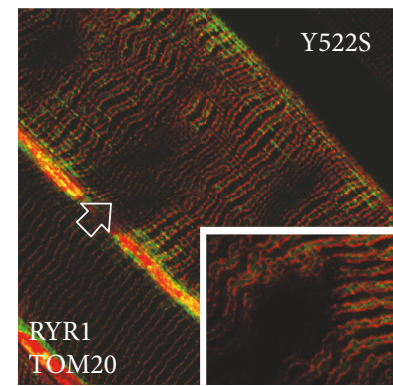

(c)

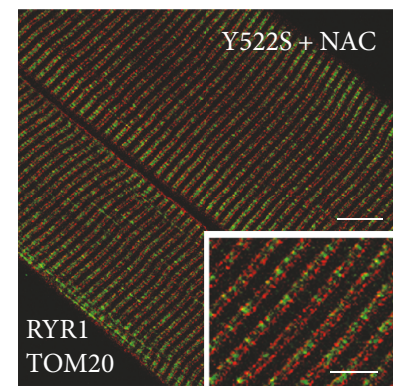

(e)

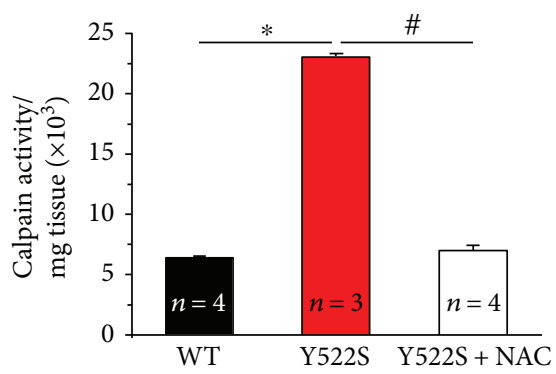

(g)

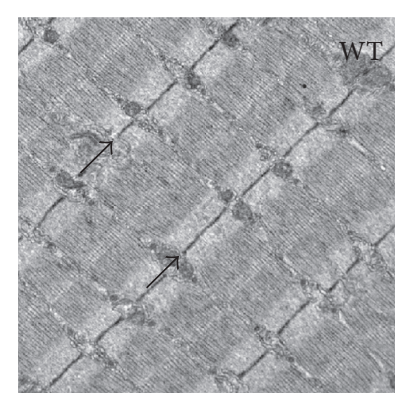

(b)

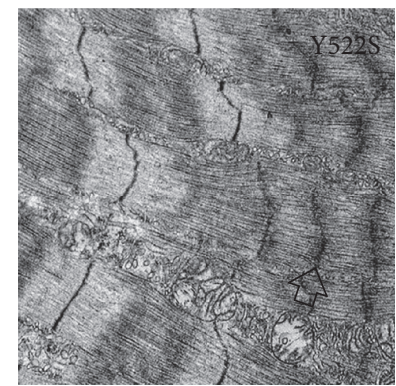

(d)

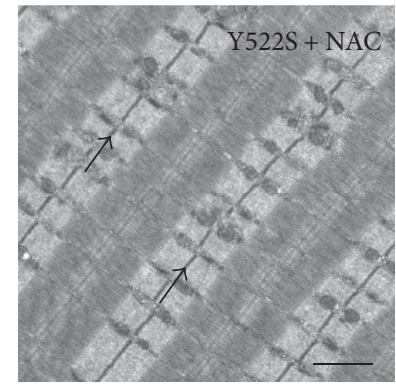

(f)

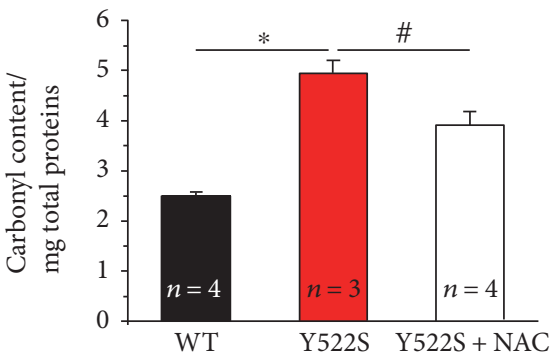

(h)

FIGURE 2: Fiber ultrastructure, calpain activity, and carbonyl protein content at 4 months of age. (a-f) Representative immunofluorescence and EM images showing fluorescent cross striation (a, c, and e) and myofibrillar/sarcomeric organization (b, d, and f) in EDL fibers. In (b) and (f), small arrows point at $Z$-lines, while in (c and d) large arrows point to areas in which cross striation and sarcomeric structure are compromised. (g) Calpain activity expressed in total hind limb muscle homogenates. (h) Carbonyl protein content in EDL muscle homogenates. In (g and $\mathrm{h}$ ), data are given as mean $\pm \mathrm{SEM} ;{ }^{*} p<0.05$, WT versus RYR ${ }^{\mathrm{Y} 522 \mathrm{~S} / \mathrm{WT}}$ mice; ${ }^{*} p<0.05$, untreated RYR ${ }^{\mathrm{Y} 522 \mathrm{~S} / \mathrm{WT}}$ versus NAC-treated RYR1 ${ }^{\text {Y522S/WT }}$ mice. In ( $\mathrm{g}$ and h), $n=$ number of mice. Scale bars in (a, c, and e) $10 \mu \mathrm{m}$ (insets $5 \mu \mathrm{m}$ ); in (b, d, and f) $1 \mu \mathrm{m}$.

case, the total amount of carbonyl proteins, which was abnormally elevated in RYR1 $1^{\mathrm{Y} 22 \mathrm{~S} / \mathrm{WT}}$, was lowered of about $20 \%$ by NAC treatment, although it remained still higher than that in WT (Figure 2(h)).

3.2. NAC Treatment Improves In Vivo Grip Strength and Ex Vivo Muscle Contractile Function in RYR1 $1^{Y 522 S / W T}$ Mice. As
NAC treatment was very effective in protecting muscle fibers of RYR1 ${ }^{\mathrm{Y} 522 \mathrm{~S} / \mathrm{WT}}$ mice from structural damage, we performed in vivo grip strength test and ex vivo contractile experiments on intact EDL muscles, to evaluate whether NAC was also able to improve muscle function of RYR1 ${ }^{\text {Y522S/WT }}$ knock-in mice. Grip strength was evaluated at 3 different time points between 2 (beginning of the short- 


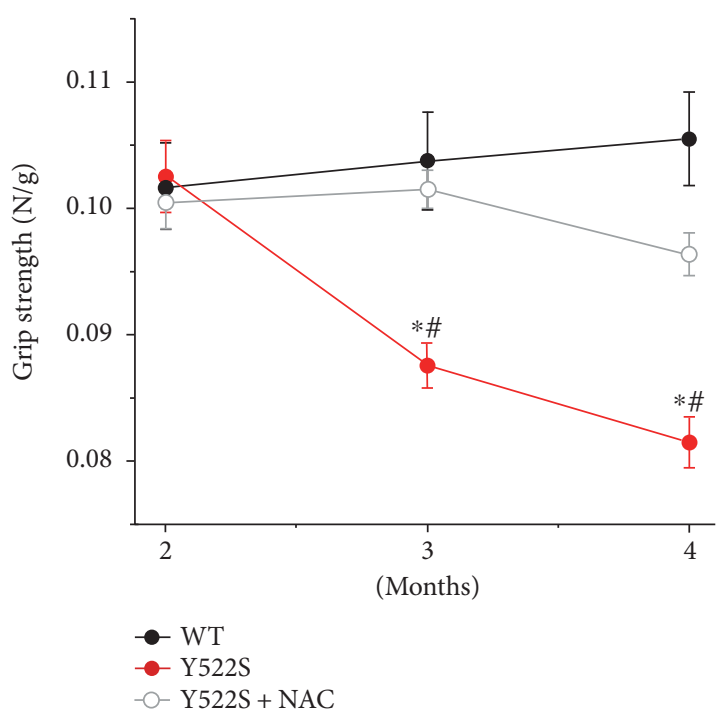

(a)

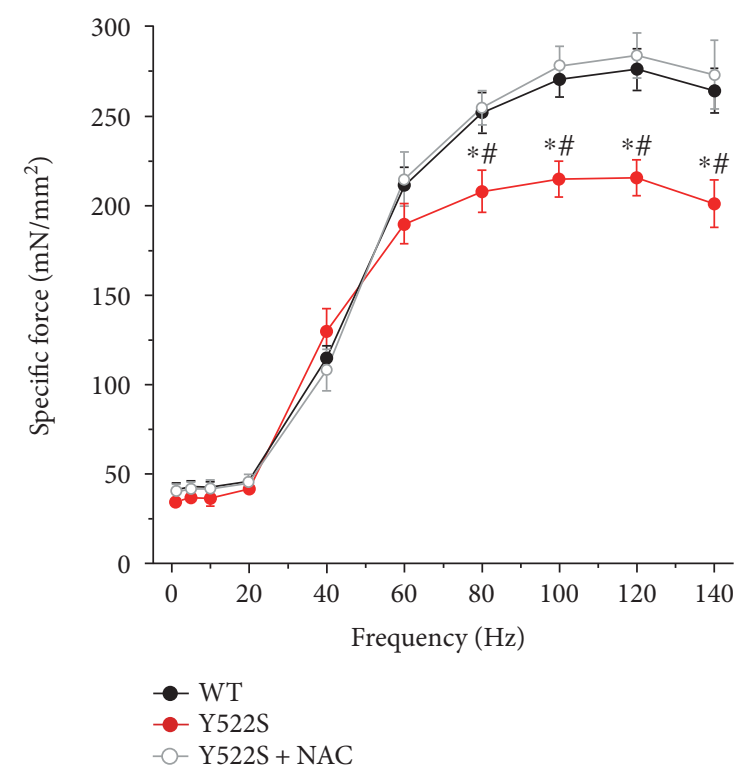

(c)

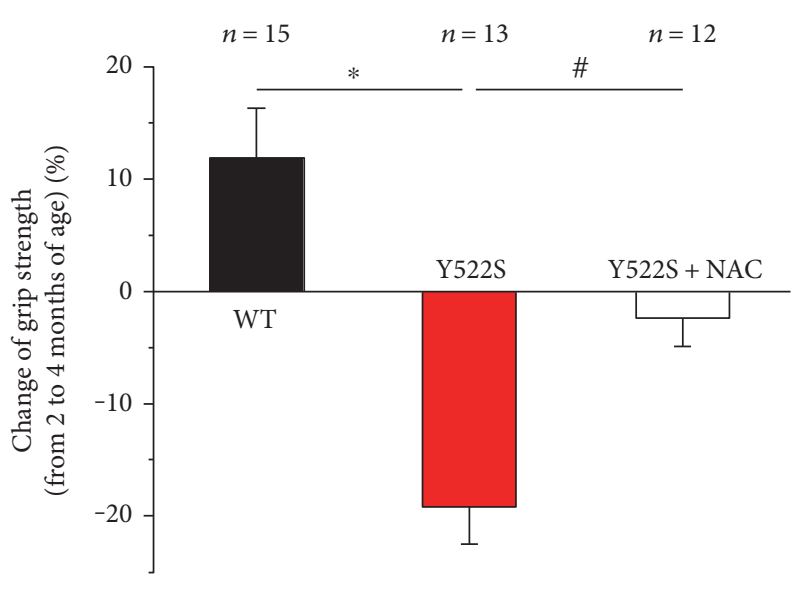

(b)

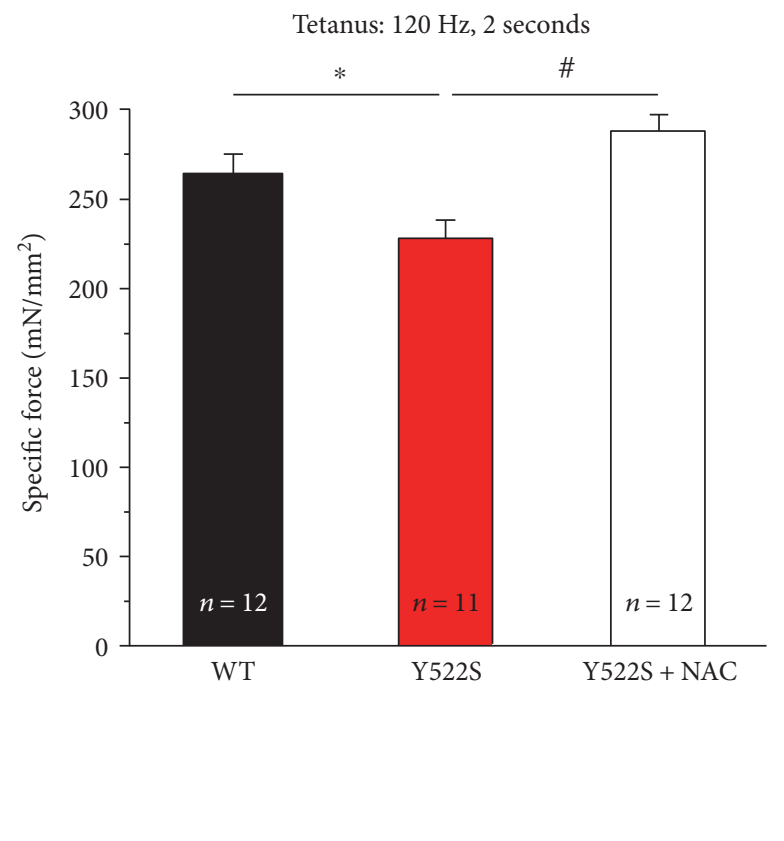

(d)

Figure 3: In vivo grip strength and ex vivo specific force at 4 months of age. (a) Time-course of grip strength from 2 (beginning of short-term NAC treatment) to 4 months (end of short-term NAC treatment) of age expressed as force on body weight (N/g). (b) Change in grip strength from 2 to 4 months of age (shown as a percentage). (c and d) Force-frequency (1-140 Hz) relationship curves of specific force (c) and specific force during a single $2 \mathrm{~s}, 120 \mathrm{~Hz}$ stimulation train $(\mathrm{d})$ recorded for the same EDL muscles. Data are given as mean \pm SEM; ${ }^{*} p<0.05$, WT versus RYR1 ${ }^{\text {Y522S/WT }}$ mice; ${ }^{*} p<0.05$, untreated RYR $1^{\mathrm{Y} 522 \mathrm{~S} / \mathrm{WT}}$ versus NAC-treated RYR $1^{\mathrm{Y} 522 \mathrm{~S} / \mathrm{WT}}$ mice. In (b), $n=$ number of mice; in (d), $n=$ number of EDL muscles.

term NAC treatment) and 4 months of age (end of short-term NAC treatment). Results of these evaluations of force are plotted in Figures 3(a) and 3(b). While no significant difference was found among the three groups of mice tested at 2 months of age, in the following 2 months, (a) WT mice showed a small, but progressive, rise in grip strength of about $10 \%$; (b) untreated RYR1 $1^{\text {Y522S/WT }}$ mice exhibited a pronounced decay, with a force reduction of about $20 \%$; and finally (c) NAC-treated RYR1 $1^{\mathrm{Y} 522 \mathrm{~S} / \mathrm{WT}}$ mice displayed an ameliorated muscle function compared to untreated RYR $1^{\text {Y522S/WT }}$ mice, with a reduction in grasp force of only $4 \%$. To verify if NAC treatment directly improved muscle function, we evaluated ex vivo force-frequency and 2second tetanic force in isolated EDL muscles at 4 months of age using an in vitro setting (Figures 3(c) and 3(d)). The force-frequency relationship curves during high-frequency stimulation (from $80 \mathrm{~Hz}$ to $140 \mathrm{~Hz}$ ) plotted in Figure 3(c) showed that EDL muscles from RYR1 ${ }^{\mathrm{Y} 522 \mathrm{~S} / \mathrm{WT}}$ mice 


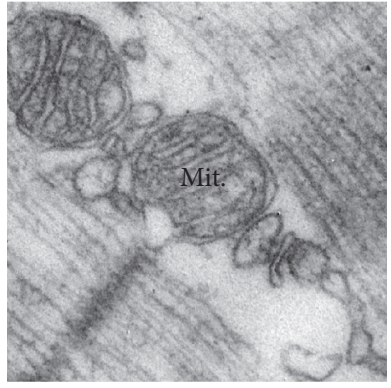

(a)

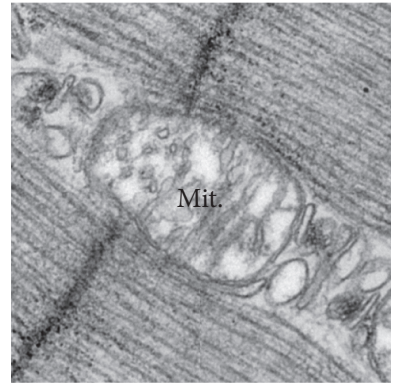

(b)

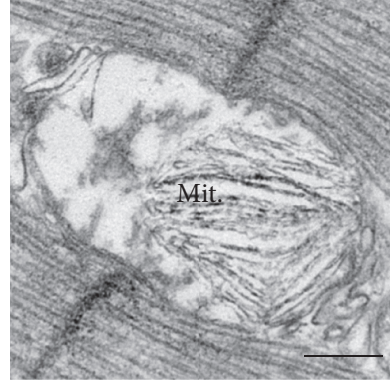

(c)
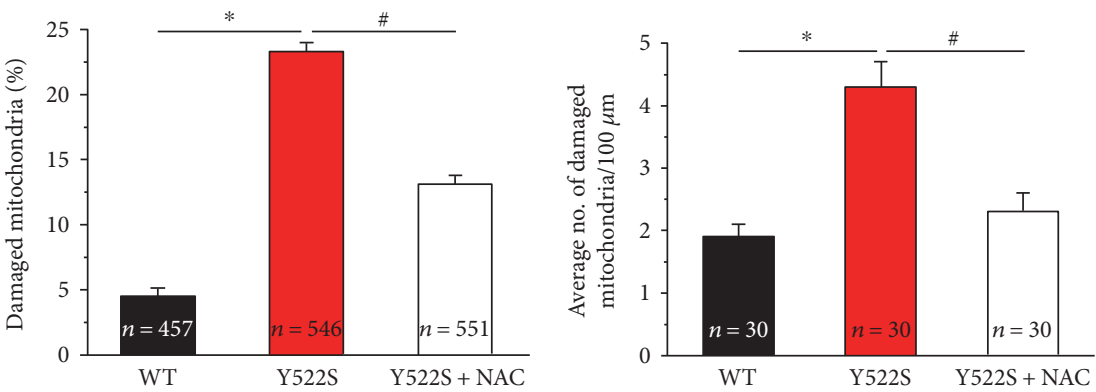

(d)

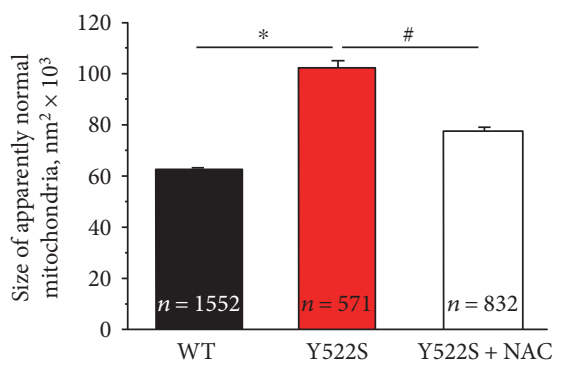

(f)

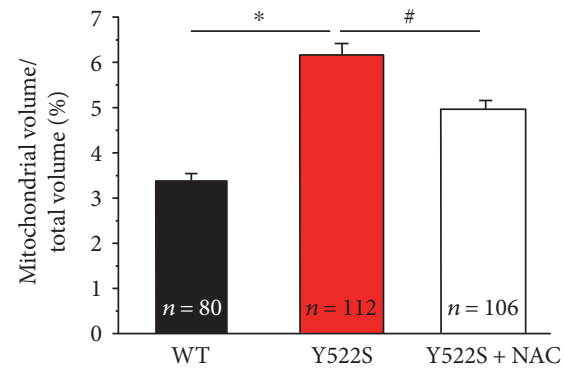

(g)

FIgURe 4: Mitochondrial damage, size, and volume at 4 months of age. (a-c) Representative EM images displaying apparently normal (a) and damaged mitochondria (b and c). (d) Percentage of damaged mitochondria. (e) Average number of damaged mitochondria/area of EM section. (f) Average size of apparently normal mitochondria (i.e., mitochondria not included in the quantitative analysis of (d and e)). (g) Percentage of fiber volume occupied by mitochondria. See also Table S2. Data are given as mean \pm SEM; ${ }^{*} p<0.05$, WT versus $\mathrm{RYR}^{\mathrm{Y} 522 \mathrm{~S} / \mathrm{WT}}$ mice; ${ }^{\#} p<0.05$, untreated RYR1 ${ }^{\mathrm{Y} 522 \mathrm{~S} / \mathrm{WT}}$ versus NAC-treated RYR1 ${ }^{\mathrm{Y} 522 \mathrm{~S} / \mathrm{WT}}$ mice. In (d and f), $n=$ number of measurements; in (e and g), $n=$ number of fibers analyzed. Scale bar: $0.1 \mu \mathrm{m}$.

developed a specific force $\left(\mathrm{mN} / \mathrm{mm}^{2}\right)$ significantly lower than that from WT, force that was efficiently rescued by NAC treatment. Interestingly, the percentage of relative force, normalized to the maximum $\left(F_{0}\right)$, for the half-maximal frequency $\left(\mathrm{Hz}_{60}\right)$ was significantly higher in RYR1 ${ }^{\mathrm{Y} 522 \mathrm{~S} / \mathrm{WT}}$ muscles $(87.7 \pm 2.8)$ than that in the WT $(74.8 \pm 7.4)$ and NAC-treated RYR1 ${ }^{\mathrm{Y} 522 \mathrm{~S} / \mathrm{WT}}(77.0 \pm 5.6)$ muscles (Supplementary Figure S2 A). We also evaluated the maximal force developed by the same EDL muscles by applying a single train stimulus $(120 \mathrm{~Hz}$ for 2 seconds) to generate a fused tetanus (Figure 3(d)). EDL muscles from RYR1 ${ }^{\mathrm{Y} 522 \mathrm{~S} / \mathrm{WT}}$ mice exhibited a maximal specific tetanic force significantly lower to that developed by EDL muscles from WT mice (227.2 \pm 11.6 versus $264.0 \pm 10.6 \mathrm{mN} / \mathrm{mm}^{2}$ ); while following two months of NAC treatment, maximal specific tetanic force expressed by EDL muscles from RYR1 ${ }^{\mathrm{Y} 522 \mathrm{~S} / \mathrm{WT}}$ mice was rescued to values similar to those of WT muscles $\left(287.7 \pm 8.8 \mathrm{mN} / \mathrm{mm}^{2}\right.$ ) (Figure 3(d)).

3.3. NAC Treatment Reduces Mitochondrial Swelling and Damage in EDL Muscle of RYR $1^{Y 522 S / W T}$ Mice. As previously reported, mitochondrial damage underlies formation of cores in RYR1 ${ }^{\mathrm{Y} 522 \mathrm{~S} / \mathrm{WT}}$ mice [17]. Here, we confirmed previous findings: (a) damaged mitochondria (such as those in Figures $4(\mathrm{~b})$ and $4(\mathrm{c})$ ) were significantly more frequent in EDL fibers from RYR1 ${ }^{\mathrm{Y} 522 \mathrm{~S} / \mathrm{WT}}$ mice than in WT (Figures 4(d) and 4(e)); (b) also, mitochondria that are apparently normal (dark appearance, such as that in Figure 4(a)) were larger in size, suggesting that the organelles are swollen (Figure 4(f)); (c) total mitochondrial volume was increased in fibers from RYR1 ${ }^{\mathrm{Y} 522 \mathrm{~S} / \mathrm{WT}}$ (Figure 4(g)). Short-term NAC treatment significantly rescued all these 
features: (a) the number of mitochondria presenting structural damage was decreased in fibers from mice treated with NAC (Figures 4(d) and 4(e)); (b) treatment of RYR1 ${ }^{\text {Y522S/WT }}$ mice with NAC was also effective in reducing the size of apparently normal mitochondria and the relative fiber volume occupied by these organelles (Figures $4(\mathrm{f})$ and $4(\mathrm{~g})$ ). Data plotted in Figures 4(d), 4(e), 4(f), and 4(g) are reported in Table S2.

As in adult skeletal muscle, mitochondria are usually closely associated with CRUs [20]; here, we verified whether NAC exert a beneficial effect on the CRU-mitochondrial interaction. We evaluated the frequency of mitochondria, CRUs, and mitochondria-CRU pairs (Supplementary Figure S1): (a) number/area of both mitochondria and CRUs is decreased in RYR1 $1^{\mathrm{Y} 522 \mathrm{~S} / \mathrm{WT}}$ compared to that in WT (Supplementary Figure S1 B and C), which in turn causes a great reduction in the number/area of mitochondria-CRU pairs (Supplementary Figure S1 D). Treatment with NAC was able to partially rescue the number/area of mitochondria (Supplementary Figure S1 B) and of mitochondria-CRU pairs (Supplementary Figure S1 D). However, NAC was not able to rescue the number/area of CRUs (Supplementary Figure S1 C). Data plotted in Supplementary Figure S1 $\mathrm{B}-\mathrm{C}$ are reported in Table S3.

3.4. NAC Was Effective in Preventing Decay of Muscle Structure/Function in RYR $1^{Y 522 S / W T}$ Mice Also during LongTerm Treatment. We have previously shown that fiber damage in RYR1 ${ }^{\mathrm{Y} 522 \mathrm{~S} / \mathrm{WT}}$ mice becomes quite severe with increasing age [17]. Here, we tested the long-term efficacy of $\mathrm{NAC}$ in reducing/preventing structural and functional decay of RYR $1^{\mathrm{Y} 522 \mathrm{~S} / \mathrm{WT}}$ fibers by treating mice for 6 months with NAC, starting at 4 months of age when structural damage was already at an advanced stage. Results of these experiments are shown in Figure 5: (a) the percentage of fibers presenting unstructured and contracture cores (resp., 18\% and $30 \%$ in RYR1 ${ }^{\text {Y522S/WT }}$ mice) was significantly reduced (10\% and $13 \%$, resp.) by NAC administration (Figure 5(a)). Data plotted in Figure 5(a) are reported in Table S4. As done in samples from 4-month-old mice treated for 2 months, we also measured blood levels of CK and LDH at 10 months of age following 6 months of NAC treatment: both CK and $\mathrm{LDH}$ were significantly elevated in $\mathrm{RYR} 1^{\mathrm{Y} 522 \mathrm{~S} / \mathrm{WT}}$ muscles compared to WT, but significantly lowered by NAC (Figures 5(b) and 5(c)).

Rescue of muscle damage by the long-term NAC treatment was also accompanied by functional improvements (Figures 5(d), 5(e), 5(f), and 5(g)). Indeed, although grip strength from 4 to 10 months of age show a slight decrease in all groups of animals (Figure 5(d)), the timedependent decay of strength was significantly more pronounced in RYR $1^{\mathrm{Y} 522 \mathrm{~S} / \mathrm{WT}}$ mice ( - 30\%), compared to both WT $(\sim-10 \%)$ and NAC-treated RYR1 ${ }^{\mathrm{Y} 522 \mathrm{~S} / \mathrm{WT}}(\sim-10 \%)$ mice (Figure 5(e)). Finally, long-term NAC treatment was also effective in restoring the kinetic-contractility properties (i.e., force frequency and tetanic force) of isolated EDL muscles from RYR $1^{\text {Y522S/WT }}$ mice, which were weaker than WT when untreated (Figures 5(f) and 5(g) and Supplementary Figure S2 B).
3.5. NAC Treatment Reduces 3-Nitrotyrosine (3-NT) and SOD2 Levels in Skeletal Muscle from RYR1 $1^{Y 522 S / W T}$ Mice. We measured in WT, and in untreated or NAC-treated RYR1 ${ }^{\text {Y522S/WT }}$ mice (both at 4 and 10 months of age), (i) levels of 3-Nitrotyrosine (3-NT), a product of nitration of tyrosine residues of proteins mediated by RNS such as peroxynitrite anion and nitrogen dioxide, which are indicators of oxidative protein damage and inflammation [31-34]; (ii) expression levels of superoxide dismutase types 1 and 2 (SOD1 and SOD2), the two main intracellular enzymes, respectively, localized in the cytoplasm and within mitochondrial matrix, that catalyze the dismutation of anion $\left(\mathrm{O}_{2}^{\bullet-}\right)$ into $\mathrm{O}_{2}$ and hydrogen peroxide $\left(\mathrm{H}_{2} \mathrm{O}_{2}\right)$ [35-37], the first step in the elimination of reactive species of oxygen (ROS). WB analyses (Figure 6(a and e)), performed on total hind limb muscle homogenates, revealed that the amount of 3-NT was significantly higher in RYR $1^{\mathrm{Y} 522 \mathrm{~S} / \mathrm{WT}}$ compared to WT mice, with a $\sim 1.5$-fold increase (Figure 6 (b and $\mathrm{f}$ )). NAC treatment normalized 3-NT level to values similar to those of WT mice (Figure 6(a, b, e, and $\mathrm{f})$ ). In the same samples, we also measured SOD1 and SOD2 protein contents (Figure 6(a and e)): while there were no differences in SOD1 levels among the three groups of mice (Figure 6(a, c, $\mathrm{e}$, and $\mathrm{g})$ ), SOD2 in RYR1 ${ }^{\mathrm{Y} 522 \mathrm{~S} / \mathrm{WT}}$ muscles was $\sim 1.5$ times higher than that in WT muscles (Figure 6(a, d, e, and h)); also, in this case, NAC treatment brought back SOD2 levels to values closer to those of WT (Figure 6(a, d, e, and h)).

\section{Discussion}

The substitution of a tyrosine with a serine in position 522 (Y522S) of RYR1 results in gain-of-function of the SR Ca ${ }^{2+}$ release channel linked, in humans, to $\mathrm{MH}$ with formation of cores [10]. The expression of this mutation in an animal model successfully reproduced the human phenotype, as heterozygous RYR $1^{\text {Y522S/WT }}$ knock-in mice are MH susceptible [15] and develop structural abnormalities resembling human CCD [17]. The formation of unstructured and contracture cores in RYR1 ${ }^{\mathrm{Y} 522 \mathrm{~S} / \mathrm{WT}}$ muscle fibers is initiated by mitochondrial damage, with abnormalities that then extend to sarcotubular system and contractile elements [17]. The mechanisms linking the RYR1 mutation to the mitochondrial damage in RYR1 ${ }^{\mathrm{Y} 522 \mathrm{~S} / \mathrm{WT}}$ muscle fibers are still not fully understood: one possibility is that $\mathrm{Ca}^{2+}$-dependant overproduction of ROS and RNS plays a direct role in the destruction of mitochondria $[16,17]$.

4.1. Main Findings of the Present Paper: NAC Ameliorates Structure and Function of RYR1 $1^{Y 522 S / W T}$ Muscle by Reducing Oxidative Stress. NAC was previously used to reduce oxidative stress and normalize $\mathrm{SR} \mathrm{Ca}^{2+}$ release in RYR1 ${ }^{\text {Y522S/WT }}$ mice and in [16] mice lacking calsequestrin1 (CASQ1-null) $[19,38]$. NAC treatment also reduced the rate of mortality [19] and prevented mitochondrial damage [39] in CASQ1-null mice that, similarly to RYR1 ${ }^{\mathrm{Y} 522 \mathrm{~S} / \mathrm{WT}}$ mice, triggers lethal $\mathrm{MH}$ episodes when exposed to halogenated anesthetics and heat $[40,41]$. The results of the present paper demonstrate that NAC treatment in RYR1 ${ }^{\mathrm{Y} 522 \mathrm{~S} / \mathrm{WT}}$ mice (i) reduces formation of unstructured and contracture 


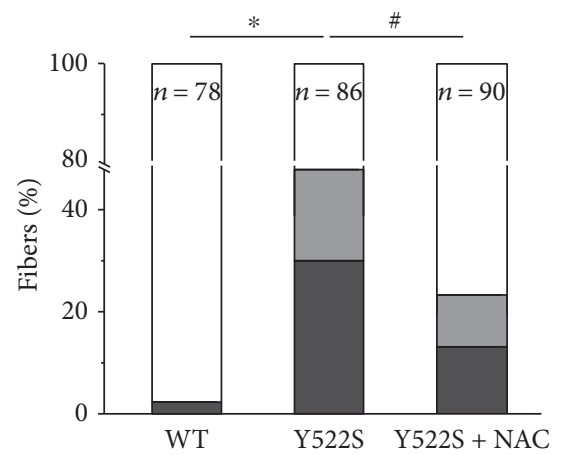

(a)

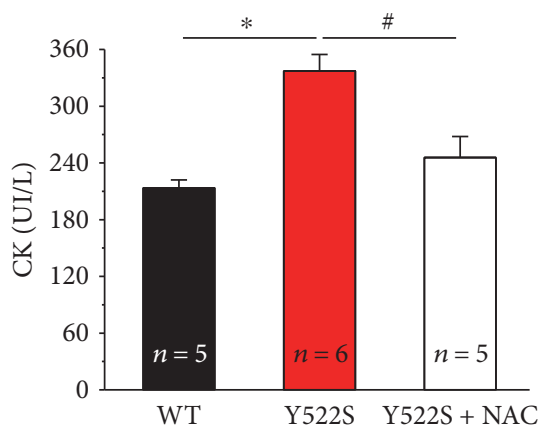

(b)

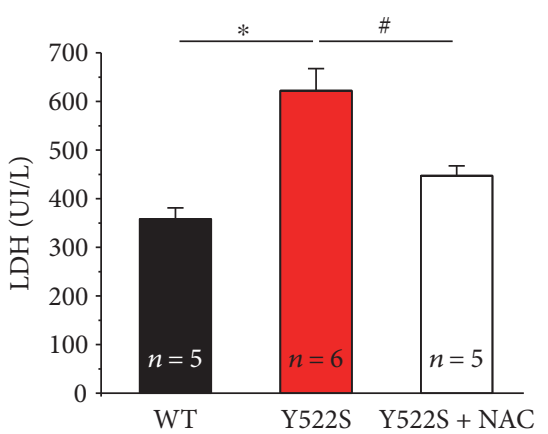

(c)

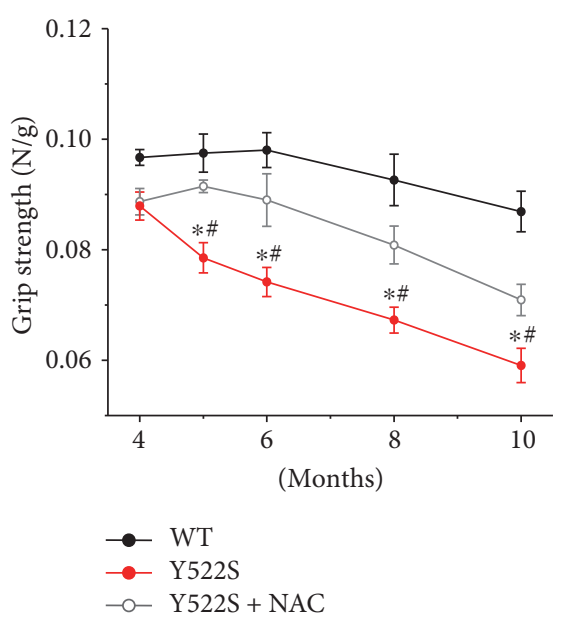

(d)

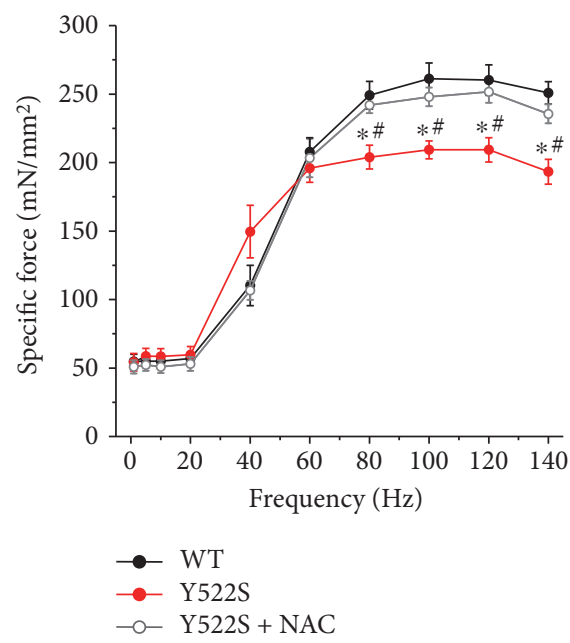

(f)

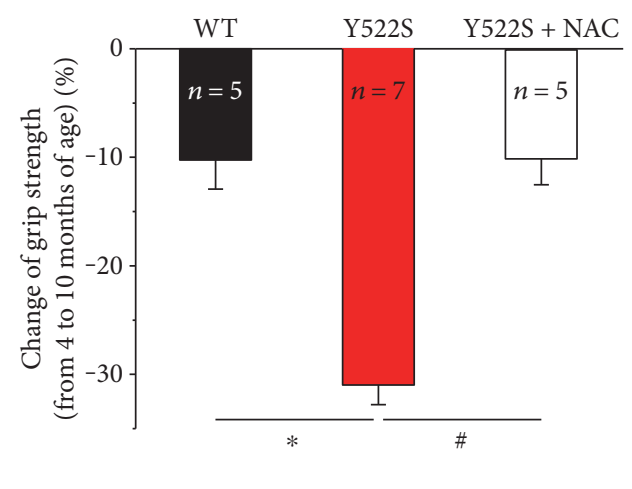

(e)

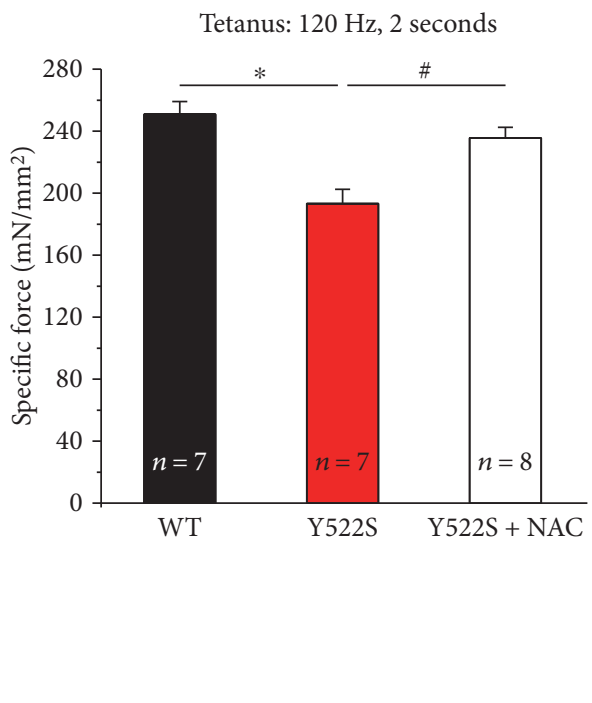

(g)

FIGURE 5: Effects of long-term NAC treatment at 10 months of age. (a) Quantitative analysis of EDL fibers presenting the features classified in Figures 1(a), 1(b), and 1(c) shown as percentage of fibers analyzed (white: normal fibers; grey: fibers with unstructured cores; and dark grey: fibers with contracture cores). See also Table S4. (b and c) Serum levels of creatine kinase (CK) and lactate dehydrogenase (LDH). (d) Time course of grip strength from 4 (beginning of long-term NAC treatment) to 10 months (end of long-term NAC treatment) of age expressed as force on body weight (N/g). (e) Change in grip strength from 4 to 10 months of age (shown as a percentage). (f and g) Force-frequency $(1-140 \mathrm{~Hz})$ relationship curves of specific force (f) and specific force during a single $2 \mathrm{~s}, 120 \mathrm{~Hz}$ stimulation train (g) recorded for the same EDL muscles. In s (b-g), data are given as mean \pm SEM; ${ }^{*} p<0.05$, WT versus RYR $1^{\mathrm{Y} 522 \mathrm{~S} / \mathrm{WT}}$ mice; ${ }^{*} p<0.05$, untreated RYR ${ }^{\mathrm{Y} 522 \mathrm{~S} / \mathrm{WT}}$ versus NAC-treated RYR1 ${ }^{\text {Y522S/WT }}$ mice. In (a), $n=$ number of EDL fibers analyzed; in (b-e), $n=$ number of mice; in (f and g), $n=$ number of EDL muscles. 


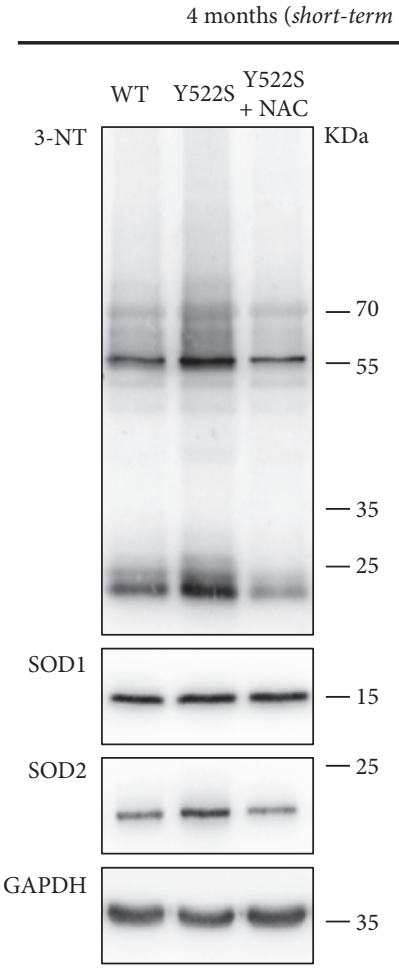

(a)

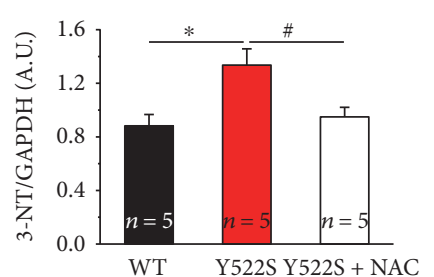

(b)

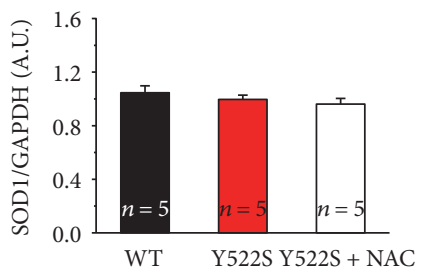

(c)

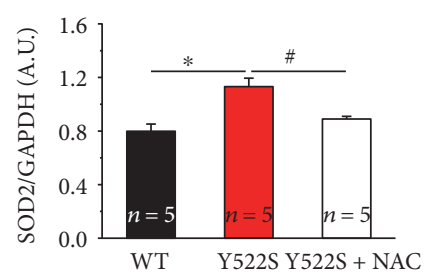

(d)

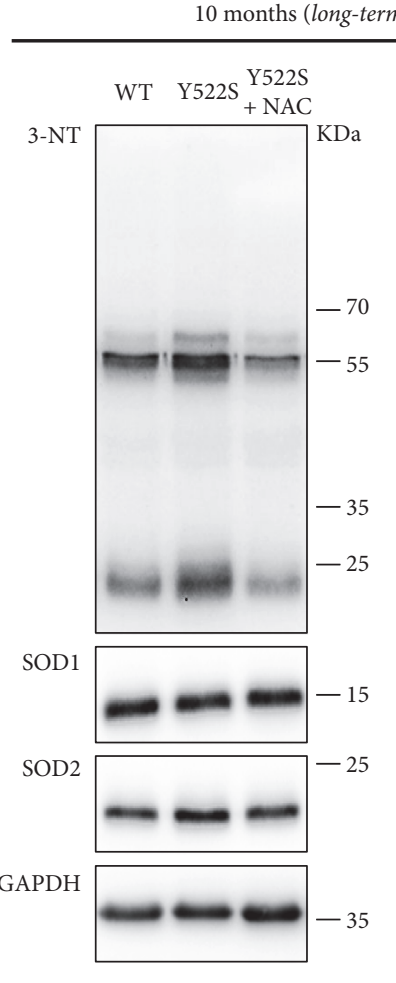

(e)

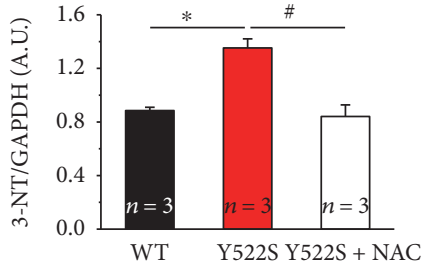

(f)

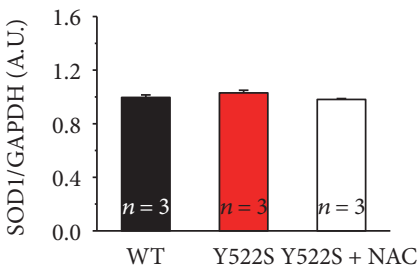

(g)

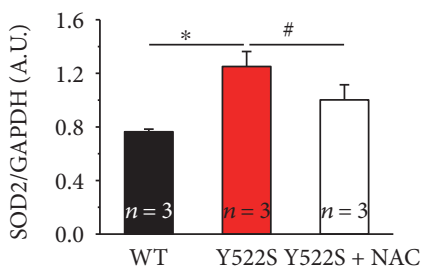

(h)

FIGURE 6: Oxidative stress markers at 4 and 10 months of age following either short- or long-term treatment. (a and e) Representative immunoblots showing expression of 3-Nitrotyrosine (3-NT), SOD1, and SOD2 in total hind limb muscle homogenates. (b-d) and (f-h) Relative band densities normalized to GAPDH levels. Data are given as mean $\pm \mathrm{SEM} ;{ }^{*} p<0.05$, WT versus RYR ${ }^{\mathrm{Y} 522 \mathrm{~S} / \mathrm{WT}}$ mice; ${ }^{\#} p<0.05$, untreated RYR $1^{\mathrm{Y} 522 \mathrm{~S} / \mathrm{WT}}$ versus NAC-treated RYR $1^{\mathrm{Y} 522 \mathrm{~S} / \mathrm{WT}}$ mice. $n=$ number of mice.

cores (Figures 1 and 2) and (ii) improves muscle function, both in vivo (grip strength) and ex vivo during electrical stimulation of isolated EDLs (Figure 3). The beneficial effect of NAC treatment on structure/function of RYR $1^{\text {Y522S/WT }}$ muscles is evident both when mice were treated starting at 2 months of age, that is, when mitochondrial and fiber damage was still minimal, but also in mice treated for extended periods (6 months of NAC administration; Figure 5) starting at 4 months of age when structural damage was already at an advanced stage, as quantitative analysis in Figure 4 points to significant protection from mitochondrial damage. The reduced formation of cores in NAC-treated RYR1 $1522 \mathrm{~S} / \mathrm{WT}$ mice could result from the beneficial effect that this treatment exerts on mitochondrial morphology (Figure 4), as we have previously shown that mitochondrial damage plays a pivotal role in the formation of structural cores in this mouse model [17].

The role that oxidative stress plays in the events leading to mitochondrial damage and formation of cores in CCD has been long discussed. Our present data shows that in NAC-treated RYR1 ${ }^{\text {Y522S/WT }}$ mice, displaying improved fiber structure/function and reduced mitochondrial damage (Figures 1, 2, 3, 4, and 5), oxidative stress is significantly lower than that in untreated RYR1 ${ }^{\mathrm{Y} 522 \mathrm{~S} / \mathrm{WT}}$ mice (Figure 6). In line with these data, we have previously shown that treatment with antioxidants (NAC and Trolox) also lowered oxidative stress in mice with a similar phenotype [19, 39]. Specifically, levels of 3-NT and SOD2, but not of SOD1, which were significantly increased in RYR $1^{\text {Y522S/WT }}$ muscles, are reduced to levels more similar to WT following both short- and long-term NAC treatments (Figure 6). In general, the augmented expression of SOD1 and SOD2 likely reflects a compensatory response to excessive production of ROS [42], a finding in agreement with the observation that the expression of both isoforms increased under different physiopathological conditions in which oxidative stress is elevated [23, 43-46]. The fact that the SOD2 isoform, but not SOD1, is upregulated (Figure 6) suggests that (a) the $\mathrm{O}_{2}{ }^{\bullet-}$ generated in the mitochondrial matrix plays a central role in the elevated oxidative stress damaging mitochondria and fibers in RYR1 $1^{\mathrm{Y} 522 \mathrm{~S} / \mathrm{WT}}$ muscles [18] and (b) the effect of mitochondrial-targeted antioxidants should be tested in future studies.

4.2. Possible Molecular Mechanisms Linking Excessive SR $\mathrm{Ca}^{2+}$ Leak to Oxidative Stress, Mitochondrial Damage, and Formation of Cores. In RYR1 ${ }^{\mathrm{Y} 522 \mathrm{~S} / \mathrm{WT}}$ fibers, myoplasmic $\mathrm{Ca}^{2+}$ and oxidative stress are both chronically elevated $[16,18]$. The Y522S gain-of-function mutation is directly responsible of excessive SR $\mathrm{Ca}^{2+}$ leak, whereas the elevated oxidative stress could result from (a) excessive mitochondrial $\mathrm{Ca}^{2+}$ uptake, which is known to stimulate the aerobic 
metabolism $[47,48]$ and/or (b) increased ATP demand due to the constant need of actively removing excessive myoplasmic $\mathrm{Ca}^{2+}$ (by ATP-dependent reuptake into the SR or extrusion in the extracellular space). In turn, $\mathrm{Ca}^{2+}$ leak and oxidative stress are linked together in a loop where ROS/RNS results in oxidative modifications of RYR1 channel that enhances the opening probability of the channel and, thus, further $\mathrm{Ca}^{2+}$ release from the SR [16]. The accumulation of myoplasmic $\mathrm{Ca}^{2+}$ could also result from ROS/RNS-dependent decrease in the activity of both sarcoplasmic/endoplasmic reticulum $\mathrm{Ca}^{2+}$ ATPase (SERCA) [49] and plasma membrane $\mathrm{Ca}^{2+}$-ATPase (PMCA). Although mitochondrial $\mathrm{Ca}^{2+}$ uptake in RYR1 ${ }^{\mathrm{Y} 522 \mathrm{~S} / \mathrm{WT}}$ fibers has not been directly measured, chronic elevation of myoplasmic $\mathrm{Ca}^{2+}$ could likely result in mitochondrial $\mathrm{Ca}^{2+}$ overload, loss of mitochondrial membrane potential, and swelling $[50,51]$. The precise disposition of mitochondria next to CRUs (which contain RYR1) in skeletal muscle fibers [20], and their cross talkbased $\mathrm{Ca}^{2+}$ signaling [52-56], places these organelles in the unfortunate location to be directly exposed to the excessive $\mathrm{Ca}^{2+}$ leak through the mutated RYR1-Y522S channel. In ongoing experiments, we are currently investigating mitochondrial $\mathrm{Ca}^{2+}$ uptake in RYR1 ${ }^{\mathrm{Y} 522 \mathrm{~S} / \mathrm{WT}}$ fibers.

Chronic $\mathrm{Ca}^{2+}$ elevation and ROS/RNS overproduction are likely key players also in proteolysis of contractile elements and oxidation of proteins and lipids of intracellular organelles, such as CRUs and mitochondria. Increased intracellular $\mathrm{Ca}^{2+}$ concentration has been linked to muscle damage, mitochondrial swelling, and degeneration of myofibrils, [57-59] and activation of calpains, one of the most important nonlysosomal classes of proteases in skeletal muscle fibers, is indeed activated by increased $\mathrm{Ca}^{2+}$ levels [60-62] and by excessive oxidative stress [34, 63, 64]. Activation of calpains has been shown to promote degradation of specific sarcomeric proteins such as titin [24] and disruption of myofibrils $[34,65,66]$. We recently reported that RYR1 ${ }^{\mathrm{Y} 522 \mathrm{~S} / \mathrm{WT}}$ and CASQ1-null mice, both having altered $\mathrm{Ca}^{2+}$ handling and elevated oxidative stress, displayed levels of calpain activity significantly higher than WT [67]. Consistent with these data, results of the present study indicate that calpain activity is significantly elevated in RYR $1^{\text {Y522S/WT }}$ muscles, suggesting that the activation of this proteolytic system could contribute to the disruption of membrane organelles and myofibrillar architecture during formation of cores. In support of this hypothesis, our data showed that NAC treatment reduces calpain levels, formation of structural cores, and mitochondrial damage (Figures 1, 2, and 4).

4.3. Conclusions. The mechanism linking mutations in RYR1 to mitochondrial damage (and consequent formation of structural cores) in human CCD has been long discussed and still far from being unraveled. Our work provides some additional insights in the pathogenic mechanisms that underlie mitochondrial damage/disappearance in cores of RYR1 $1^{\mathrm{Y} 522 \mathrm{~S} / \mathrm{WT}}$ mice, supporting the idea that $\mathrm{SR} \mathrm{Ca}^{2+}$ leak and oxidative stress do play a central role in these events. In addition, our results suggest that NAC administration (or more generally treatment with antioxidants) could be taken into consideration as a long-term therapeutic intervention to reduce the development of cores and improve muscle function in patients affected by CCD.

\section{Abbreviations}

$\begin{array}{ll}\text { CCD: } & \text { Central core disease } \\ \text { CM: } & \text { Confocal microscopy } \\ \text { CRU: } & \text { Calcium release unit } \\ \text { EC-coupling: } & \text { Excitation-contraction coupling } \\ \text { EDL: } & \text { Extensor digitorum brevis } \\ \text { EM: } & \text { Electron microscopy } \\ \text { NAC: } & \text { N-acetylcysteine } \\ \text { ROS and RNS: } & \text { Reactive oxygen and nitrogen species } \\ \text { RYR: } & \text { Ryanodine receptor } \\ \text { SR: } & \text { Sarcoplasmic reticulum } \\ \text { TT: } & \text { Transverse tubules } \\ \text { WT: } & \text { Wild type. }\end{array}$

\section{Disclosure}

The abstract of the manuscript was presented in "XII annual meeting of the interuniversity Institute of Myology."

\section{Conflicts of Interest}

The authors declare that they have no conflicts of interest.

\section{Authors' Contributions}

Simona Boncompagni and Feliciano Protasi conceived and directed the study. Antonio Michelucci, Alessandro De Marco, Flavia A. Guarnier, and Simona Boncompagni performed the experimental work and data analysis. In detail, (a) Antonio Michelucci performed the spectrophotometric analysis of $\mathrm{CK}$ and LDH levels in blood samples and the in vivo grip strength and ex vivo force and contraction kinetics of intact EDL muscles; (b) Alessandro De Marco and Simona Boncompagni performed the qualitative and quantitative light and EM analysis; (c) Alessandro De Marco performed the western blot experiments; (d) Flavia A. Guarnier performed the measurements of the calpain activity and carbonyl protein content. Finally, Simona Boncompagni, Feliciano Protasi, and Antonio Michelucci wrote the manuscript. Antonio Michelucci and Alessandro De Marco are the cofirst authors. Feliciano Protasi and Simona Boncompagni are the cosenior authors.

\section{Acknowledgments}

The authors thank Dr. S. L. Hamilton (Baylor College of Medicine, Houston, TX, USA), who generated and kindly provided the RYR1 ${ }^{\mathrm{Y} 522 \mathrm{~S} / \mathrm{WT}}$ mouse line for this study. This study was supported by the following grants: (a) Italian Telethon ONLUS Foundation (Rome, Italy): GGP13213 to Feliciano Protasi; (b) Italian Ministry of Education, University and Research (Rome, Italy): RBFR13A20K to Simona Boncompagni; (c) Italian Ministry of Health, (Rome, Italy): GR-2011-02352681 to Simona Boncompagni; and (d) National Institute of Health (Bethesda, MD, U.S.A): AR053349-06 (subcontract to Feliciano Protasi). 


\section{References}

[1] K. R. Magee and G. M. Shy, "A new congenital nonprogressive myopathy," Brain, vol. 79, no. 4, pp. 610-621, 1956.

[2] H. Jungbluth, "Central core disease," Orphanet Journal of Rare Diseases, vol. 2, p. 25, 2007.

[3] V. Dubowitz and A. G. Pearse, "Oxidative enzymes and phosphorylase in central-core disease of muscle," Lancet, vol. 2, no. 7140, pp. 23-24, 1960.

[4] K. Hayashi, R. G. Miller, and A. K. Brownell, "Central core disease: ultrastructure of the sarcoplasmic reticulum and Ttubules," Muscle \& Nerve, vol. 12, no. 2, pp. 95-102, 1989.

[5] D. H. Maclennan and E. Zvaritch, "Mechanistic models for muscle diseases and disorders originating in the sarcoplasmic reticulum," Biochimica et Biophysica Acta, vol. 1813, no. 5, pp. 948-964, 2011.

[6] C. Franzini-Armstrong and F. Protasi, "Ryanodine receptors of striated muscles: a complex channel capable of multiple interactions," Physiological Reviews, vol. 77, no. 3, pp. 699729, 1997.

[7] M. F. Schneider, "Control of calcium release in functioning skeletal muscle fibers," Annual Review of Physiology, vol. 56, pp. 463-484, 1994.

[8] M. A. Denborough, K. C. Hopkinson, and D. G. Banney, "Firefighting and malignant hyperthermia," British Medical Journal (Clinical Research Edition), vol. 296, no. 6634, pp. 1442-1443, 1988.

[9] D. H. MacLennan, K. Otsu, J. Fujii et al., "The role of the skeletal muscle ryanodine receptor gene in malignant hyperthermia," Symposia of the Society for Experimental Biology, vol. 46, pp. 189-201, 1992.

[10] K. A. Quane, J. M. Healy, K. E. Keating et al., "Mutations in the ryanodine receptor gene in central core disease and malignant hyperthermia," Nature Genetics, vol. 5, no. 1, pp. 51-55, 1993.

[11] M. A. Denborough, X. Dennett, and R. M. Anderson, "Centralcore disease and malignant hyperpyrexia," British Medical Journal, vol. 1, no. 5848, pp. 272-273, 1973.

[12] G. D. Eng, B. S. Epstein, W. K. Engel, D. W. McKay, and R. McKay, "Malignant hyperthermia and central core disease in a child with congenital dislocating hips," Archives of Neurology, vol. 35, no. 4, pp. 189-197, 1978.

[13] G. B. Frank, "The current view of the source of trigger calcium in excitation-contraction coupling in vertebrate skeletal muscle," Biochemical Pharmacology, vol. 29, no. 18, pp. 2399-2406, 1980.

[14] A. Shuaib, R. T. Paasuke, and K. W. Brownell, "Central core disease. Clinical features in 13 patients," Medicine (Baltimore), vol. 66, no. 5, pp. 389-396, 1987.

[15] M. G. Chelu, S. A. Goonasekera, W. J. Durham et al., "Heat- and anesthesia-induced malignant hyperthermia in an RyR1 knock-in mouse," The FASEB Journal, vol. 20, no. 2, pp. 329-330, 2006.

[16] W. J. Durham, P. Aracena-Parks, C. Long et al., "RyR1 Snitrosylation underlies environmental heat stroke and sudden death in Y522S RyR1 knockin mice," Cell, vol. 133, no. 1, pp. 53-65, 2008.

[17] S. Boncompagni, A. E. Rossi, M. Micaroni et al., "Characterization and temporal development of cores in a mouse model of malignant hyperthermia," Proceedings of the National Academy of Sciences of the United States of America, vol. 106, no. 51, pp. 21996-22001, 2009.

[18] L. Wei, G. Salahura, S. Boncompagni et al., "Mitochondrial superoxide flashes: metabolic biomarkers of skeletal muscle activity and disease," The FASEB Journal, vol. 25, no. 9, pp. 3068-3078, 2011.

[19] A. Michelucci, C. Paolini, M. Canato et al., "Antioxidants protect calsequestrin-1 knockout mice from halothane- and heat-induced sudden death," Anesthesiology, vol. 123, no. 3, pp. 603-617, 2015.

[20] S. Boncompagni, A. E. Rossi, M. Micaroni et al., "Mitochondria are linked to calcium stores in striated muscle by developmentally regulated tethering structures," Molecular Biology of the Cell, vol. 20, no. 3, pp. 1058-1067, 2009.

[21] B. A. Mobley and B. R. Eisenberg, "Sizes of components in frog skeletal muscle measured by methods of stereology," The Journal of General Physiology, vol. 66, no. 1, pp. 31-45, 1975.

[22] A. V. Loud, "A method for the quantitative estimation of cytoplasmic structures," The Journal of Cell Biology, vol. 15, no. 3, pp. 481-487, 1962.

[23] L. Pietrangelo, A. D'Incecco, A. Ainbinder et al., "Agedependent uncoupling of mitochondria from $\mathrm{Ca}^{2+}$ release units in skeletal muscle," Oncotarget, vol. 6, no. 34, pp. 3535835371, 2015.

[24] D. E. Goll, V. F. Thompson, H. Li, W. Wei, and J. Cong, "The calpain system," Physiological Reviews, vol. 83, no. 3, pp. 731-801, 2003.

[25] A. Z. Reznick and L. Packer, "Oxidative damage to proteins: spectrophotometric method for carbonyl assay," Methods in Enzymology, vol. 233, pp. 357-363, 1994.

[26] D. Weber, M. J. Davies, and T. Grune, "Determination of protein carbonyls in plasma, cell extracts, tissue homogenates, isolated proteins: focus on sample preparation and derivatization conditions," Redox Biology, vol. 5, pp. 367-380, 2015.

[27] A. M. Connolly, R. M. Keeling, S. Mehta, A. Pestronk, and J. R. Sanes, "Three mouse models of muscular dystrophy: the natural history of strength and fatigue in dystrophin-, dystrophin/utrophin-, and laminin alpha2-deficient mice," Neuromuscular Disorders, vol. 11, no. 8, pp. 703-712, 2001.

[28] P. Brancaccio, G. Lippi, and N. Maffulli, "Biochemical markers of muscular damage," Clinical Chemistry and Laboratory Medicine, vol. 48, no. 6, pp. 757-767, 2010.

[29] J. Huang and N. E. Forsberg, "Role of calpain in skeletalmuscle protein degradation," Proceedings of the National Academy of Sciences of the United States of America, vol. 95, no. 21, pp. 12100-12105, 1998.

[30] J. Huang and X. Zhu, "The molecular mechanisms of calpains action on skeletal muscle atrophy," Physiological Research, vol. 65 , no. 4, pp. 547-560, 2016.

[31] K. Ogino and D. H. Wang, "Biomarkers of oxidative/nitrosative stress: an approach to disease prevention," Acta Medica Okayama, vol. 61, no. 4, pp. 181-189, 2007.

[32] T. Grune, K. Merker, T. Jung, N. Sitte, and K. J. Davies, "Protein oxidation and degradation during postmitotic senescence," Free Radical Biology \& Medicine, vol. 39, no. 9, pp. 1208-1215, 2005.

[33] T. Jung, M. Engels, B. Kaiser, D. Poppek, and T. Grune, "Intracellular distribution of oxidized proteins and proteasome in HT22 cells during oxidative stress," Free Radical Biology \& Medicine, vol. 40, no. 8, pp. 1303-1312, 2006. 
[34] S. K. Powers, J. Duarte, A. N. Kavazis, and E. E. Talbert, "Reactive oxygen species are signalling molecules for skeletal muscle adaptation," Experimental Physiology, vol. 95, no. 1, pp. 1-9, 2010.

[35] J. M. McCord and I. Fridovich, "The utility of superoxide dismutase in studying free radical reactions. I. Radicals generated by the interaction of sulfite, dimethyl sulfoxide, and oxygen," The Journal of Biological Chemistry, vol. 244, no. 22, pp. 6056-6063, 1969.

[36] S. Marklund and G. Marklund, "Involvement of the superoxide anion radical in the autoxidation of pyrogallol and a convenient assay for superoxide dismutase," European Journal of Biochemistry, vol. 47, no. 3, pp. 469-474, 1974.

[37] I. Fridovich, "Superoxide anion radical $\left(\mathrm{O}_{2}^{-}\right)$, superoxide dismutases, and related matters," The Journal of Biological Chemistry, vol. 272, no. 30, pp. 18515-18517, 1997.

[38] C. Paolini, M. Quarta, A. Nori et al., "Reorganized stores and impaired calcium handling in skeletal muscle of mice lacking calsequestrin-1," The Journal of Physiology, vol. 583, Part 2, pp. 767-784, 2007.

[39] C. Paolini, M. Quarta, L. Wei-LaPierre et al., "Oxidative stress, mitochondrial damage, and cores in muscle from calsequestrin-1 knockout mice," Skeletal Muscle, vol. 5, p. 10, 2015.

[40] M. Dainese, M. Quarta, A. D. Lyfenko et al., "Anesthetic- and heat-induced sudden death in calsequestrin-1-knockout mice," The FASEB Journal, vol. 23, no. 6, pp. 1710-1720, 2009.

[41] F. Protasi, C. Paolini, and M. Dainese, "Calsequestrin-1: a new candidate gene for malignant hyperthermia and exertional/ environmental heat stroke," The Journal of Physiology, vol. 587, Part 13, pp. 3095-3100, 2009.

[42] F. A. Guarnier, A. L. Cecchini, A. A. Suzukawa et al., "Time course of skeletal muscle loss and oxidative stress in rats with Walker 256 solid tumor," Muscle \& Nerve, vol. 42, no. 6, pp. 950-958, 2010.

[43] J. M. Gutteridge and B. Halliwell, Radicals in Biology and Medicine, Oxford University Press, Oxford, Fourth edition, 2007.

[44] M. H. Disatnik, J. Dhawan, Y. Yu et al., "Evidence of oxidative stress in mdx mouse muscle: studies of the pre-necrotic state," Journal of the Neurological Sciences, vol. 161, no. 1, pp. 77-84, 1998.

[45] J. M. Lawler, W. Song, and S. R. Demaree, "Hindlimb unloading increases oxidative stress and disrupts antioxidant capacity in skeletal muscle," Free Radical Biology \& Medicine, vol. 35, no. 1, pp. 9-16, 2003.

[46] P. M. Abruzzo, S. di Tullio, C. Marchionni et al., "Oxidative stress in the denervated muscle," Free Radical Research, vol. 44, no. 5, pp. 563-576, 2010.

[47] R. M. Denton and J. G. McCormack, "The calcium sensitive dehydrogenases of vertebrate mitochondria," Cell Calcium, vol. 7, no. 5-6, pp. 377-386, 1986.

[48] P. R. Territo, S. A. French, and R. S. Balaban, "Simulation of cardiac work transitions, in vitro: effects of simultaneous $\mathrm{Ca}^{2+}$ and ATPase additions on isolated porcine heart mitochondria," Cell Calcium, vol. 30, no. 1, pp. 19-27, 2001.

[49] S. K. Powers and M. J. Jackson, "Exercise-induced oxidative stress: cellular mechanisms and impact on muscle force production," Physiological Reviews, vol. 88, no. 4, pp. 12431276, 2008.

[50] Q. Chen, Y. C. Chai, S. Mazumder et al., "The late increase in intracellular free radical oxygen species during apoptosis is associated with cytochrome c release, caspase activation, and mitochondrial dysfunction," Cell Death and Differentiation, vol. 10, no. 3, pp. 323-334, 2003.

[51] W. Wang, H. Fang, L. Groom et al., "Superoxide flashes in single mitochondria," Cell, vol. 134, no. 2, pp. 279-290, 2008.

[52] R. Rudolf, M. Mongillo, P. J. Magalhaes, and T. Pozzan, "In vivo monitoring of $\mathrm{Ca}^{2+}$ uptake into mitochondria of mouse skeletal muscle during contraction," The Journal of Cell Biology, vol. 166, no. 4, pp. 527-536, 2004.

[53] C. Caputo and P. Bolanos, "Effect of mitochondria poisoning by FCCP on $\mathrm{Ca}^{2+}$ signaling in mouse skeletal muscle fibers," Pflügers Archiv, vol. 455, no. 4, pp. 733-743, 2008.

[54] A. E. Rossi, S. Boncompagni, and R. T. Dirksen, "Sarcoplasmic reticulum-mitochondrial symbiosis: bidirectional signaling in skeletal muscle," Exercise and Sport Sciences Reviews, vol. 37, no. 1, pp. 29-35, 2009.

[55] A. E. Rossi, S. Boncompagni, L. Wei, F. Protasi, and R. T. Dirksen, "Differential impact of mitochondrial positioning on mitochondrial $\mathrm{Ca}^{2+}$ uptake and $\mathrm{Ca}^{2+}$ spark suppression in skeletal muscle," American Journal of Physiology. Cell Physiology, vol. 301, no. 5, pp. C1128-C1139, 2011.

[56] C. Franzini-Armstrong and S. Boncompagni, "The evolution of the mitochondria-to-calcium release units relationship in vertebrate skeletal muscles," Journal of Biomedicine \& Biotechnology, vol. 2011, Article ID 830573, 9 pages, 2011.

[57] C. J. Duncan, "Role of intracellular calcium in promoting muscle damage: a strategy for controlling the dystrophic condition," Experientia, vol. 34, no. 12, pp. 1531-1535, 1978.

[58] D. G. Allen, N. P. Whitehead, and E. W. Yeung, "Mechanisms of stretch-induced muscle damage in normal and dystrophic muscle: role of ionic changes," The Journal of Physiology, vol. 567, no. 3, pp. 723-735, 2005.

[59] A. R. Burr and J. D. Molkentin, "Genetic evidence in the mouse solidifies the calcium hypothesis of myofiber death in muscular dystrophy," Cell Death and Differentiation, vol. 22, no. 9, pp. 1402-1412, 2015.

[60] D. E. Croall and G. N. DeMartino, "Calcium-activated neutral protease (calpain) system: structure, function, and regulation," Physiological Reviews, vol. 71, no. 3, pp. 813847, 1991.

[61] P. Costelli, P. Reffo, F. Penna, R. Autelli, G. Bonelli, and F. M. Baccino, " $\mathrm{Ca}^{2+}$-dependent proteolysis in muscle wasting," The International Journal of Biochemistry \& Cell Biology, vol. 37, no. 10, pp. 2134-2146, 2005.

[62] H. Gissel, "The role of $\mathrm{Ca}^{2+}$ in muscle cell damage," Annals of the New York Academy of Sciences, vol. 1066, pp. 166-180, 2005.

[63] A. J. Smuder, A. N. Kavazis, M. B. Hudson, W. B. Nelson, and S. K. Powers, "Oxidation enhances myofibrillar protein degradation via calpain and caspase-3," Free Radical Biology \& Medicine, vol. 49, no. 7, pp. 1152-1160, 2010.

[64] E. Dargelos, C. Brule, P. Stuelsatz et al., "Up-regulation of calcium-dependent proteolysis in human myoblasts under acute oxidative stress," Experimental Cell Research, vol. 316, no. 1, pp. 115-125, 2010.

[65] T. Tiago, P. S. Palma, C. Gutierrez-Merino, and M. Aureliano, "Peroxynitrite-mediated oxidative modifications of myosin and implications on structure and function," Free Radical Research, vol. 44, no. 11, pp. 1317-1327, 2010. 
[66] M. Fedorova, N. Kuleva, and R. Hoffmann, "Identification, quantification, and functional aspects of skeletal muscle protein-carbonylation in vivo during acute oxidative stress," Journal of Proteome Research, vol. 9, no. 5, pp. 2516-2526, 2010.

[67] A. Michelucci, C. Paolini, S. Boncompagni, M. Canato, C. Reggiani, and F. Protasi, "Strenuous exercise triggers a life-threatening response in mice susceptible to malignant hyperthermia," The FASEB Journal, 2017. 


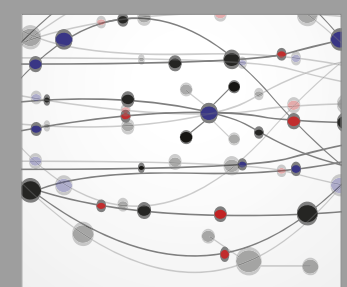

The Scientific World Journal
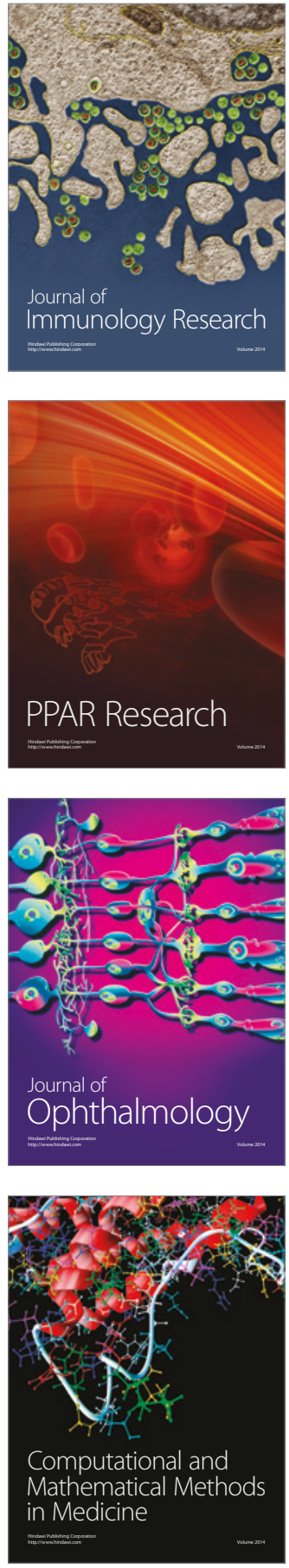

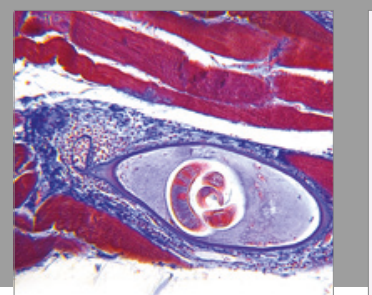

Gastroenterology Research and Practice
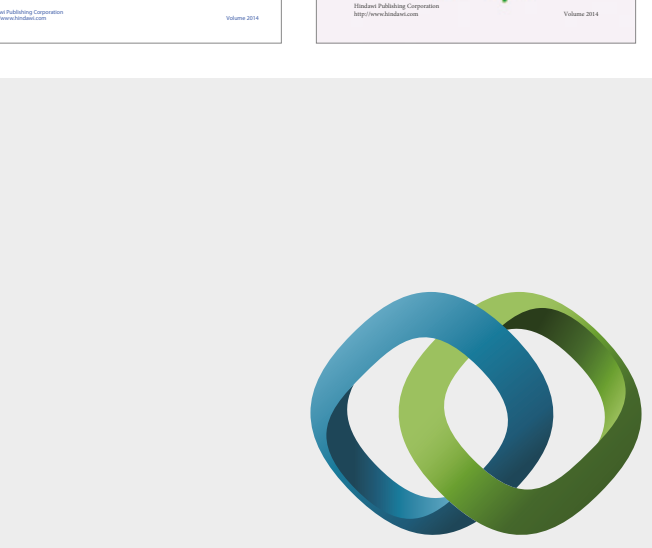

\section{Hindawi}

Submit your manuscripts at

https://www.hindawi.com
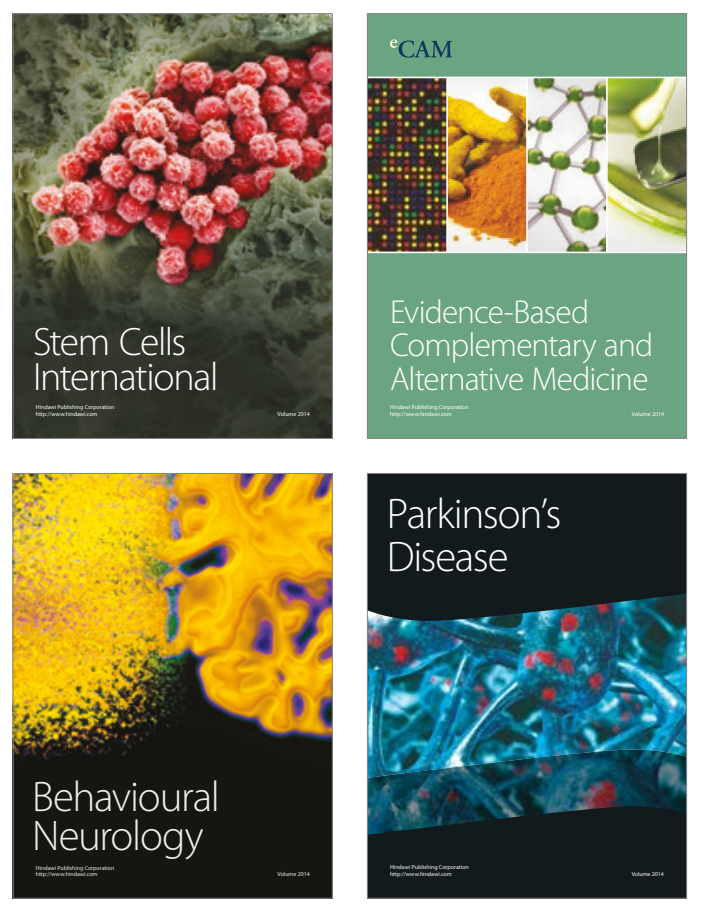
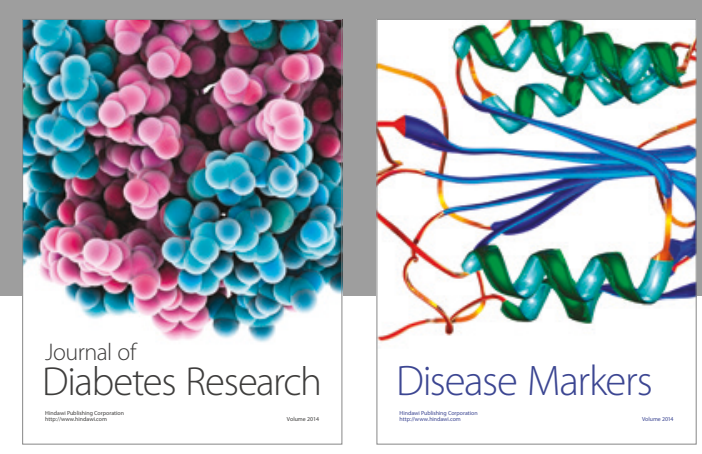

Disease Markers
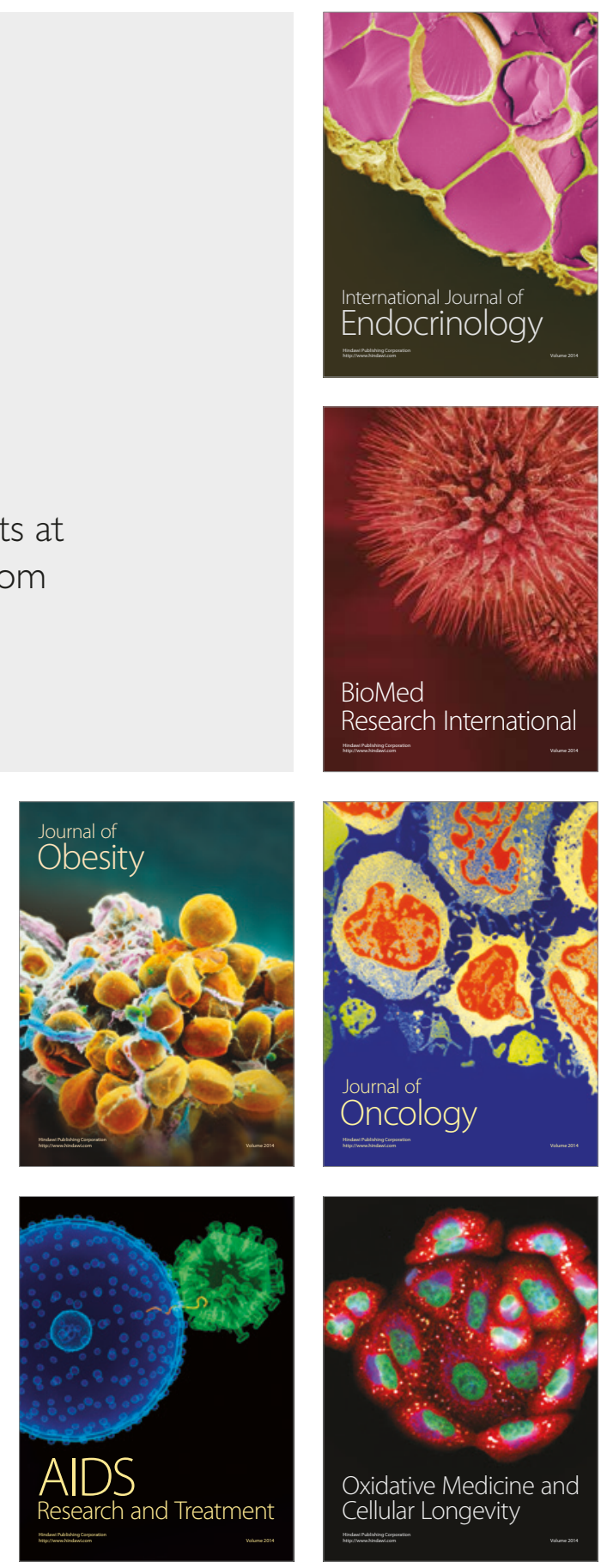